Article

\title{
Investigation of Adequate Calibration Methods for X-ray Fluorescence Core Scanning Element Count Data: A Case Study of a Marine Sediment Piston Core from the Gulf of Alaska
}

\author{
Md Nurunnabi Mondal ${ }^{1,2}{ }^{\mathbb{D}}$, Keiji Horikawa ${ }^{3, *}{ }^{(\mathbb{D}}$, Osamu Seki ${ }^{4}$, Katsuya Nejigaki ${ }^{5}$, Hideki Minami ${ }^{6}$, \\ Masafumi Murayama ${ }^{7,8}$ and Yusuke Okazaki ${ }^{9}$
}

\section{check for} updates

Citation: Mondal, M.N.; Horikawa, K.; Seki, O.; Nejigaki, K.; Minami, H.; Murayama, M.; Okazaki, Y. Investigation of Adequate Calibration Methods for X-ray Fluorescence Core Scanning Element Count Data: A Case Study of a Marine Sediment Piston Core from the Gulf of Alaska. J. Mar. Sci. Eng. 2021, 9, 540. https:// doi.org/10.3390/jmse9050540

Academic Editor: Timothy S. Collett

Received: 1 April 2021

Accepted: 13 May 2021

Published: 17 May 2021

Publisher's Note: MDPI stays neutral with regard to jurisdictional claims in published maps and institutional affiliations.

Copyright: (C) 2021 by the authors Licensee MDPI, Basel, Switzerland. This article is an open access article distributed under the terms and conditions of the Creative Commons Attribution (CC BY) license (https:// creativecommons.org/licenses/by/ $4.0 /)$.
1 Graduate School of Science and Engineering, University of Toyama, Gofuku 3190, Toyama 930-8555, Japan; nurunnabi@bsmrau.edu.bd

2 Department of Fisheries Management, Bangabandhu Sheikh Mujibur Rahman Agricultural University, Gazipur 1706, Bangladesh

3 Faculty of Science, University of Toyama, Gofuku 3190, Toyama 930-8555, Japan

4 Institute of Low Temperature Science, Hokkaido University, Sapporo, Hokkaido 060-0819, Japan; seki@pop.lowtem.hokudai.ac.jp

5 Graduate School of Integrated Arts and Sciences, Kochi University, Nankoku, Kochi 783-8502, Japan; kty.nejigaki@gmail.com

6 School of Biological Science and Engineering, Tokai University, Hokkaido 005-8601, Japan; south@tspirit.tokai-u.jp

7 Faculty of Agriculture and Marine Science, Kochi University, Nankoku, Kochi 783-8502, Japan; murayama@kochi-u.ac.jp

8 Center for Advanced Marine Core Research, Kochi University, Nankoku, Kochi 783-8502, Japan

9 Graduate School of Science, Kyushu University, Nishi-ku, Fukuoka 819-0395, Japan; okazaki.yusuke.886@m.kyushu-u.ac.jp

* Correspondence: horikawa@sci.u-toyama.ac.jp

Abstract: X-ray fluorescence (XRF) core scanner elemental count data are useful for high-resolution paleoceanographic studies. However, because several factors, such as changes in physical core properties, significantly affect element count intensities, the appropriate calibration of the count data is required. Besides, the existing approaches for calibration were not widely employed and require rigorous testing based on sediment variety. In this study, we analyzed high-resolution element intensity (cps) using a wet muddy marine sediment piston core that was collected from the northeast Gulf of Alaska and tested several approaches with ratio and log-ratio methods, and the reliability was evaluated by comparison with the concentrations that were measured by WD-XRF and an elemental analyzer. The results show that the lighter elements ( $\mathrm{Ti}$ and $\mathrm{K}$ ) exhibited a significantly weak relationship between raw counts measured by ITRAX and concentrations that were measured by the WD-XRF, indicating that some factors artificially influence ITRAX intensity data. The $\mathrm{Cl}$ intensity that is expressed as the water content in marine sediment increased significantly in the upper $202 \mathrm{~cm}$ by $42 \%$ and the top $25 \mathrm{~cm}$ by $73 \%$ as compared to the down-core (below $202 \mathrm{~cm}$ ), which deviates the $\mathrm{X}$-ray scattering and element-counts. The calibration of raw data through coherent/incoherent $\mathrm{X}$-ray scattering ratio (CIR) and additive- and centered-log ratio reduces the offsets. The calibration by CIR performed best for $\mathrm{Sr}, \mathrm{Fe}, \mathrm{Mn}, \mathrm{Ti}, \mathrm{Ca}, \mathrm{K}$, and $\mathrm{Br}\left(0.56<\mathrm{R}^{2}<0.91\right)$, and the correlation with concentration significantly increased for $\mathrm{Ti}$ and $\mathrm{K}$ of $100 \%$ and $56 \%$, respectively. Therefore, the study suggests that the correction of raw counts through CIR is an effective approach for wet marine sediment when core physical properties have greater variability.

Keywords: ITRAX; X-ray fluorescence; core scanner; calibration; coherent-incoherent ratio; WD-XRF; correlation; marine sediment; Gulf of Alaska 


\section{Introduction}

X-ray fluorescence (XRF) core scanner's non-destructive, rapid, and automated multifunction technique provides useful, high-resolution (sub-millimeter scale) geochemical records from sediment cores [1,2]. Therefore, in paleoceanographic and paleoclimatological research, the use of the XRF core scanner (CS) has increased rapidly due to its capacity for producing ultra-high-resolution elemental proxy records from the decadal to sub-annual scale. It has also the ability to analyze the elemental composition from the unprocessed sediment core, which significantly reduces the experimental cost. However, despite its rapid acquisition of high-resolution elemental datasets, it has some limitations and drawbacks. For instance, its measurements are influenced by factors, such as the variability/heterogeneity of the scanning sample, the scattering of the $\mathrm{X}$-ray radiation due to water content, and the porosity of the sediment [3-7]. Therefore, the paleo-researchers working with sediment cores still have a major debate in the use of X-ray fluorescence core scanner raw data in the paleoceanographic studies when compared to conventional measurement. Thus, to correctly interpret the XRF core scanner data, destructive elemental data measurement by inductively coupled plasma mass spectrometry (ICP-MS), conventional wavelength dispersive-XRF (WD-XRF) spectrometer, or energy dispersive-XRF (ED-XRF) spectrometer is also still needed. These conventional methods require homogenized dry powder samples that eliminate sample physical variations and heterogeneity. Although these conventional (ICP-MS, WD-/ED-XRF) techniques are well established and provide reliable datasets, they are low-resolution and discrete, time-consuming, and not cost-effective [1]. In addition, conventional methods require a complex sample preparation technique and a variety of standard and/or standard reference materials for precision and accuracy.

In fluorescence spectrometry, X-ray scattering has great importance, because the scattering (coherent, incoherent) or scattering ratios (coherent/incoherent, incoherent/coherent) are used for the normalization of X-ray fluorescence intensities [8-10]. This X-ray scattering occurred in two different ways - coherent (Rayleigh scattering), when the X-ray beam collides with an atom and deviates with no loss of energy, and incoherent (Compton scattering), when the incident X-ray loses a small fraction of its energy for the target atom's loosely bound electron [11]. Heavier (high atomic number) elements emit high X-ray fluorescence intensities with less scatter, and the lighter (low atomic number) elements emit low X-ray fluorescence intensities with high scatter. Therefore, the amount of scattering (incoherent and coherent) varies with the mean atomic number of the element [5]. The sample's physical properties and heterogeneities affect X-ray scattering. If the sediments contain high water and/or high organic matter, this favors generating high incoherent (Compton) and low coherent (Rayleigh) scattering [10]. Because water or organic matter containing low atomic numbers element $(\mathrm{H}, \mathrm{O}, \mathrm{C}$, and $\mathrm{N})$. Besides, the high water content in sediment absorbs $\mathrm{X}$-ray radiation, thus making weaker fluorescence energies [6,12]. For the normalization of $\mathrm{X}$-ray fluorescence core scanner data, previous studies used coherent [9], incoherent [13], and incoherent/coherent (inc/coh) X-ray scattering ratio [14-16]; however, very few studies used the coherent/incoherent $X$-ray scattering ratio (coh/inc) [8]. In this study, we used coherent and incoherent $X$-ray scattering for the calibration of raw ITRAX-XRF CS elements intensities together with other calibration approaches. Although, some calibration methods have been developed in order to improve the accuracy of XRF CS data $[4,8,9,12,17-21]$. The accuracy of these methods requires comprehensive evaluation based on sample types and/or sample location or instrument types (Avaatech, ITRAX, Geotek). In addition, the variability of the presented methods makes the proper selection of calibration methods complex and unclear. Therefore, these methods and their wide-ranging adaptations still need to be rigorously tested using a variety of samples.

In this study, for the development of the reliability of the ITRAX-XRF core scanning proxy use for regional to global consequences and for substrate-specific purposes, we measured the high-resolution elements' intensities (counts) by utilizing our wet muddy marine sediment piston core KH17-3 CL14PC. The core containing millimeter-scale lamination and ice-rafted debris was collected from the continental slope of the Northeastern Gulf 
of Alaska (GOA) in the northeast Pacific Ocean. The measured scanning raw intensities (count per second) were normalized through ratio and log-ratio calibration methods with several approaches under each of the groups. Furthermore, to test the accuracy of the raw and calibrated data, they were correlated with the destructive and homogenized sediment sample concentration that was measured by conventional WD-XRF and elemental analyzer, and we evaluated the methods.

\section{Materials and Methods}

\subsection{Sample Collection}

The sampling area is located at the continental slope of the Gulf of Alaska at $59^{\circ} 33.35^{\prime} \mathrm{N}$ and $144^{\circ} 09.35^{\prime} \mathrm{W}$ in the northeast Pacific Ocean. The sediment sample (piston core CL14PC) was collected from the site at $690 \mathrm{~m}$ water depth by the R/V Hakuho-Maru KH17-3 cruise in 2017 (Figure 1).

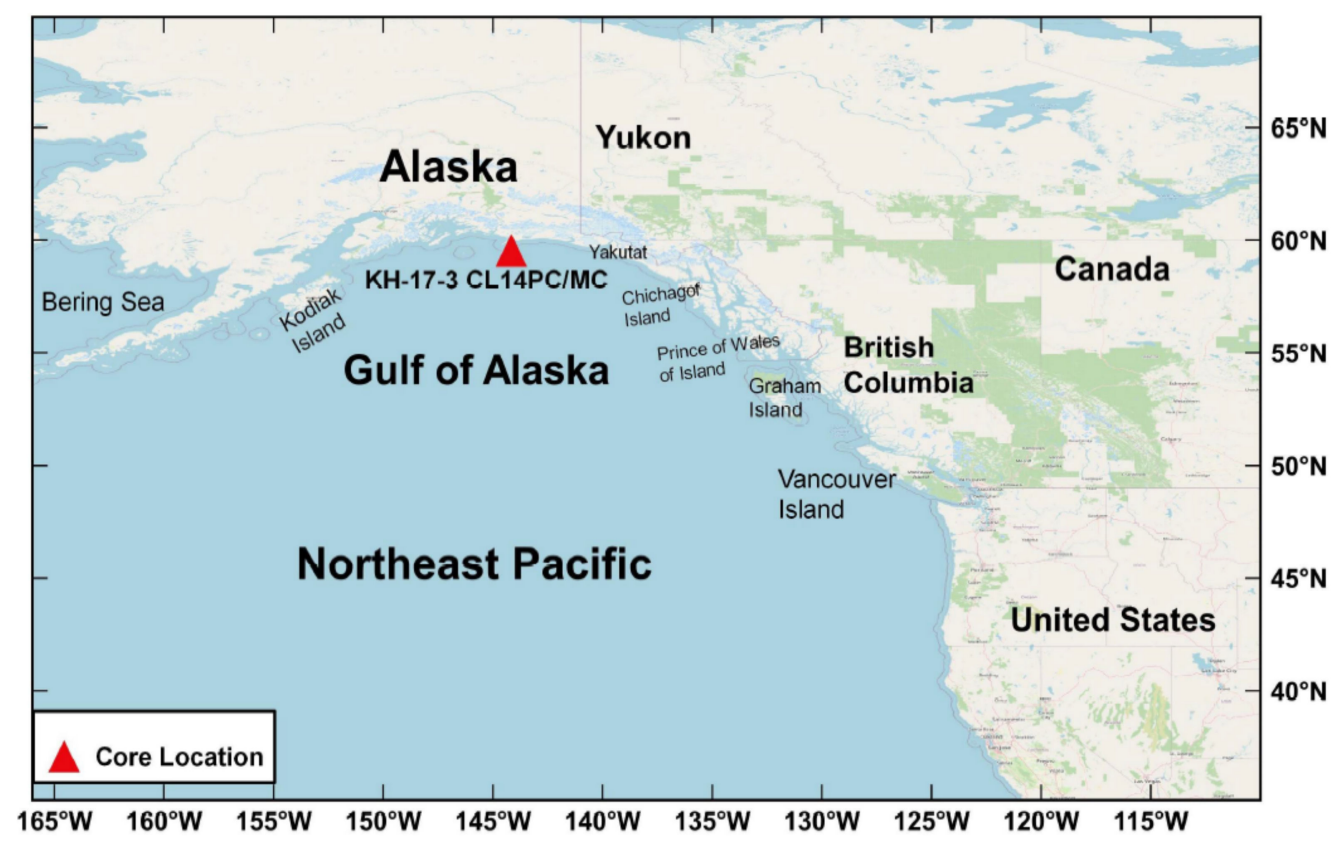

Figure 1. Map showing the location of the studied core KH-17-3 CL14PC and CL14MC (red triangle) on the Northern Gulf of Alaska continental slope in the Northeast Pacific Ocean.

\subsection{Core Description and Measurement}

We recovered the interface between the water and sediment (upper $16.5 \mathrm{~cm}$ ) by the multicore (CL14MC) sediment due to the lack of seafloor sediments in the piston core (CL14PC). The total length of the core was $869 \mathrm{~cm}$. The whole core (piston) was divided into nine sections (Figure 2). We conducted computed tomography scan (CT-scan) (Figure 3 ) and X-ray photography measurements by an X-ray CT scanner (Aquilion PRIME Focus Edition, Canon Medical System Corporation). The bulk density (gm/cc) of the core CL14PC was measured by using a Multi-Sensor Core Logger (MSCL-S, GEOTEK) gamma-ray attenuation technique at the Kochi Core Center (KCC), Nankoku, Kochi, Japan [22,23]. The MSCL-S is a non-destructive geochemical and petrophysical core logging platform that measures the bulk density, magnetic susceptibility, resistivity, and fractional porosity [22,23]. 


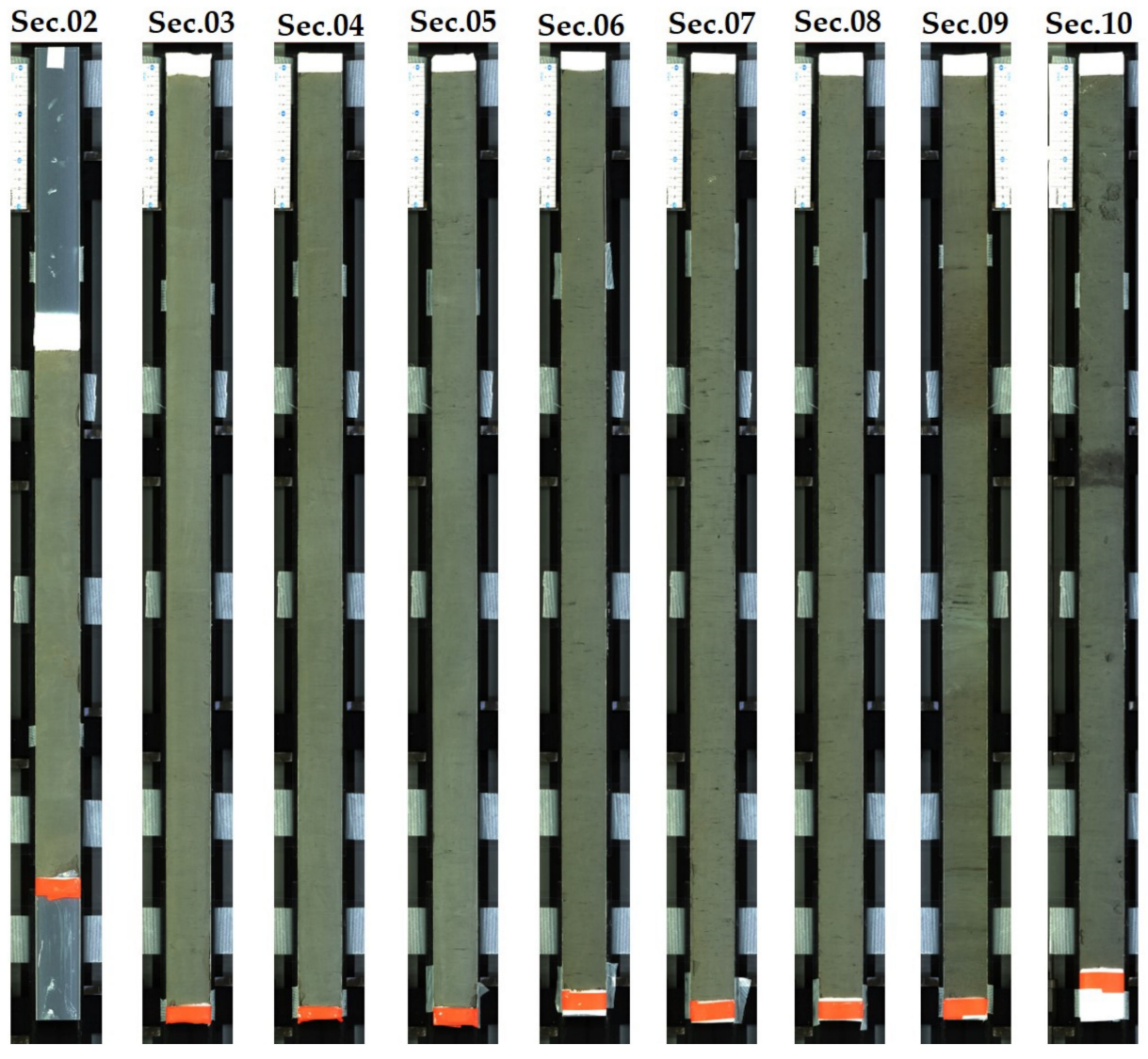

Figure 2. Section (Section 02 (Sec.02)-Section 10 (Sec.10)) pictures of the whole piston core (KH17-3 CL14PC). The number above is the section number of each section.

KH-17-3 CL14 PC WHOLE core X-ray CT

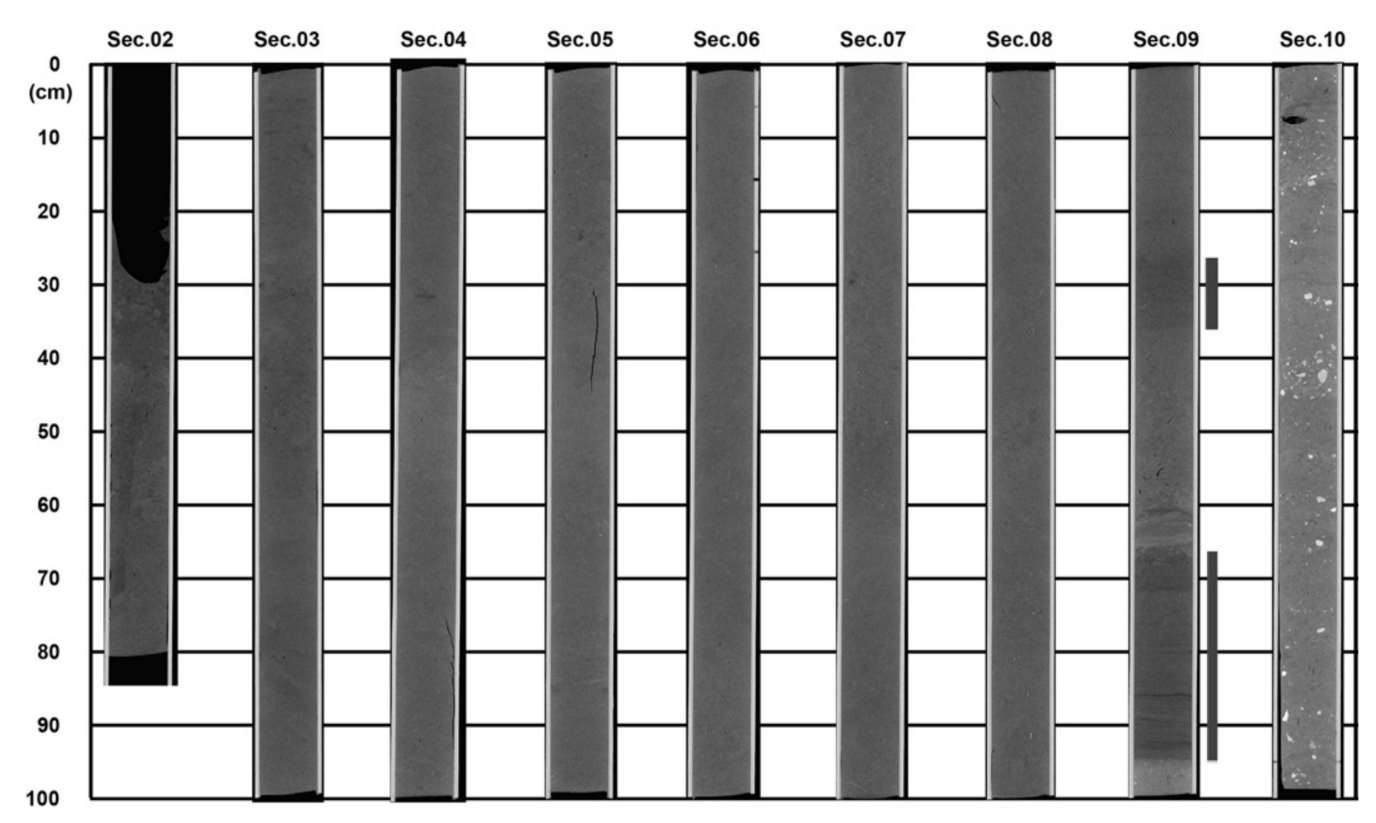

Figure 3. The computed tomographic (CT) scan photography of a total of nine sections (Sec.02-10) of the whole core KH-17-3 CL14PC. The densely area showing in Sec.09, represents the lamina and sub-lamina intervals (right side lighter black vertical line indicating the upper and lower limit of the lamina and sub-lamina intervals). Sec.10 is marked by intercalation of ice-rafted debris (white color consists of rocks, foraminiferal tests, shells, and fine grain). The black color indicated an empty and disturbed area. 
Afterward, the core sections were split into the archive and working halves for laboratory analysis. The archive half was again subdivided at $1 \mathrm{~cm}$ consecutive intervals, and the working half was subdivided at intervals of $2-2.5 \mathrm{~cm}$ and then preserved at $4{ }^{\circ} \mathrm{C}$ in a refrigerator in the laboratory of the University of Toyama, Gofuku, Toyama, Japan for further study. We define the core depth by the centimeters below the seafloor scale (hereafter cmbsf).

\subsection{Sediment Analysis}

\subsubsection{Optimization of Scanning Parameters for ITRAX-XRF Core Scanner}

To obtain the elemental profile, an ITRAX-XRF (COX analytical systems) core scanner was used at the Center for Advanced Marine Core Research (CMCR), Kochi University, Nankoku, Kochi, Japan. We made a homogenized sediment test pellet $\sim 3 \mathrm{~cm}$ wide from the sediment sample of the core CL14MC at the same site (Figure 1) to optimize the exposure time and analytical precision. By using the test sample, we conducted triplicate measurement analysis along one line with an exposure time of 10, 20, 40, and $80 \mathrm{~s}$. For scanning, we used a Molybdenum (Mo) anode X-ray tube for X-ray source setting in different voltage and current. We found that increasing the exposure time decreases the relative standard deviation (RSD\%). Some elements that are usually used in paleoceanographic studies, such as $\mathrm{Fe}, \mathrm{Ca}, \mathrm{K}, \mathrm{Ti}, \mathrm{Sr}, \mathrm{Mn}$, and $\mathrm{Br}$, have higher counts (count per second (cps)) (Figure 4) setting at $30 \mathrm{kV}$ (kilo Volt) and $55 \mathrm{~mA}$ (milli Ampere) of voltage and current, respectively, at $20 \mathrm{~s}$ exposure times. The concentration measured through WD-XRF spectrometer (see Section 2.3.5) indicating that these elements are marked by the higher concentration of $\%$ order in the sample when compared to other elements. The RSD\% of these elements was $<10 \%$ (Figure 4 ), specifically $0.52 \%, 1.57 \%, 1.24 \%, 1.76 \%, 1.97 \%, 1.82 \%$, and $5.70 \%$ for $\mathrm{Fe}$, $\mathrm{Ca}, \mathrm{K}, \mathrm{Ti}, \mathrm{Sr}, \mathrm{Mn}$, and $\mathrm{Br}$, respectively. The RSD\% that was calculated by using the mean value and standard deviation obtained from the test sample reproduced analysis (triplicate measurement) at $20 \mathrm{~s}$ exposure time through the following formula [24]:

$$
\mathrm{RSD} \%=((\sigma / \mu) \times 100)
$$

where $\sigma$ means the standard deviation and $\mu$ represents the mean values of the reproduced measurements.

However, given a low enough RSD (\%) for the target elements and the required high throughput measurement, we chose the exposure time of $20 \mathrm{~s}$ for this study, in accordance with a previous study [25]. At this exposure time (20 s) with a $30 \mathrm{kV}$ voltage and $55 \mathrm{~mA}$ current per $1 \mathrm{~cm}$ step, a total of 40-50 min is required for measurement of the $1 \mathrm{~m}$ long sediment core. Although, with this exposure time (20 s), some elements represent lower counts (cps) and higher RSD\% (Figure 4), such elements require careful attention that is related to instrument settings, including measurement time, applied current and voltage supply, and the type of X-ray source tube used. In particular, the lower- to moderateatomic number elements $\mathrm{Al}(\mathrm{Z}=13)$ and $\mathrm{Si}(\mathrm{Z}=14)$ exhibit very low counts, and, for $\mathrm{Mg}$ $(Z=12)$, no signal (counts) was found, indicating that the selected scanning parameters and molybdenum X-ray tube cannot perfectly detect these elements. Therefore, enhancement of X-ray excitation is required to detect lower-atomic number elements, although, by changing the $\mathrm{X}$-ray tube ( $\mathrm{Cr}$ tube) in the second generation ITRAX model we can obtain good detection (counts) for lower-atomic number elements [1,2]. In Figure 4, although, $\mathrm{Si}$ $(Z=14)$ shows less RSD\% value in the test sample (homogenized pellet) measurement; however, in the case of the measurements of the down-core sediment samples, we found less $\mathrm{Si}$ intensity (counts). The detection of lighter elements (like $\mathrm{Al}$ or $\mathrm{Si}$ ) through the Mo-tube is inefficient when compared to the cases of using Cr-tube [26]. Furthermore, by using a $30 \mathrm{kV}$ voltage and a $55 \mathrm{~mA}$ current at a $20 \mathrm{~s}$ exposure time, the ITRAX did not provide good intensities for the elements $\mathrm{Ni}, \mathrm{Rb}, \mathrm{Y}$, and $\mathrm{Zr}(\mathrm{Z}=28,37,39$, and 40, respectively). Therefore, by increasing the exposure time from 20 to $60 \mathrm{~s}$, or by changing the voltage and current to $45 \mathrm{kV}$ and $55 \mathrm{~mA}$, respectively, at $20 \mathrm{~s}$ ITRAX provides higher counts for these high-atomic number elements. 


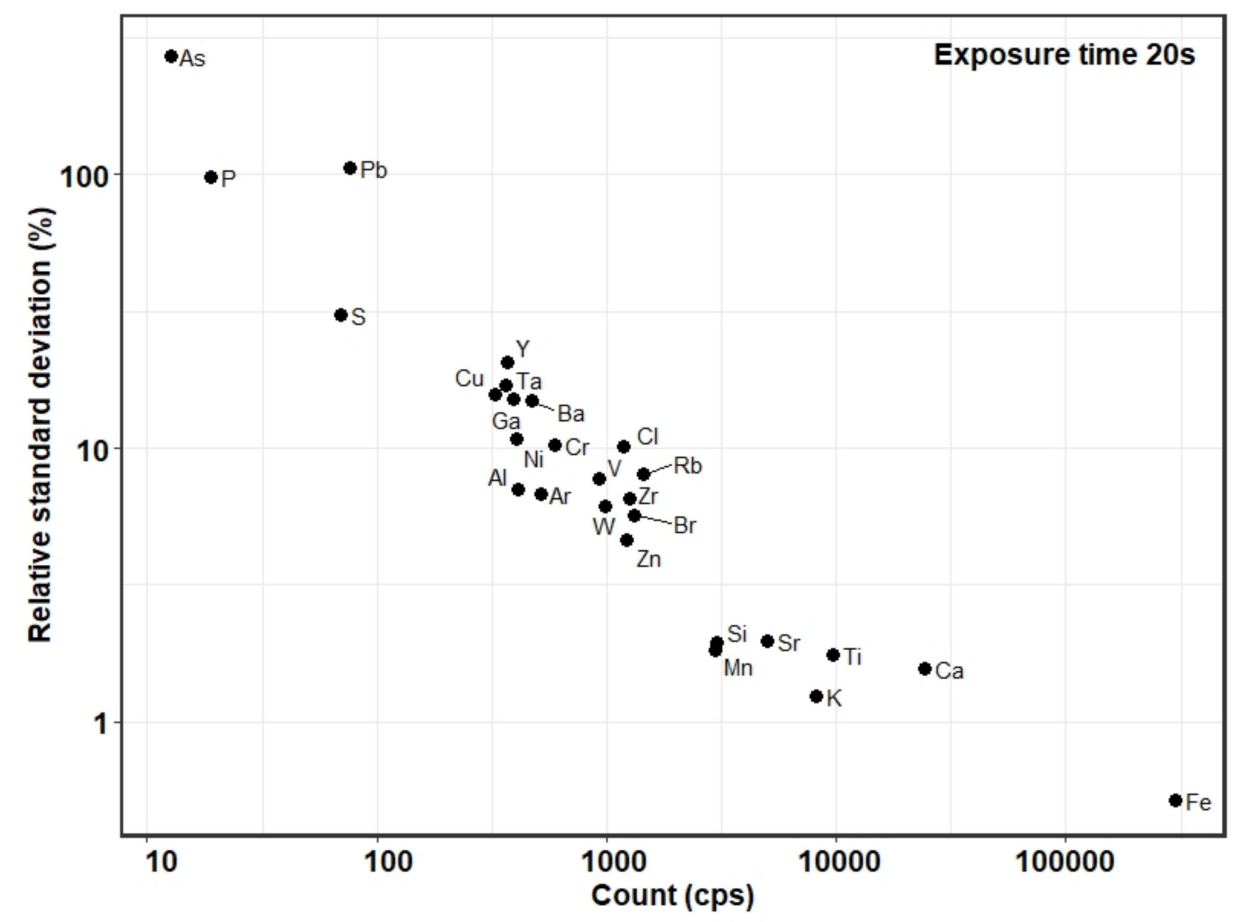

Figure 4. The relationships between count (cps) and the relative standard deviation (RSD\%) for all measured elements at $30 \mathrm{kV}$ voltage and $55 \mathrm{~mA}$ current of Mo X-ray anode tube. The exposure time (20 s) indicating at the top right corner of the plot.

\subsubsection{Measurement of Multi-Element Count through ITRAX-XRF Core Scanner}

For the measurement of the high-resolution non-destructive multi-element count, a sediment sample slab from the working half of the core CL14PC was used. To run the ITRAX core scanner, a sample slab $5 \mathrm{~cm}$ wide, $100 \mathrm{~cm}$ long, and $1 \mathrm{~cm}$ thick was used at $1 \mathrm{~cm}, 0.4 \mathrm{~mm}$, and $0.2 \mathrm{~mm}$ resolution, with a Molybdenum X-ray tube set at $30 \mathrm{kV}$ and $55 \mathrm{~mA}$ at $20 \mathrm{~s}$ exposure time. By using these scanning parameters, the core scanner detected a total of 27 elements (Al, Si, P, S, Cl, Ar, K, Ca, Ti, V, Cr, Mn, Fe, Ni, Cu, Zn, Ga, As, Br, $\mathrm{Rb}, \mathrm{Sr}, \mathrm{Y}, \mathrm{Zr}, \mathrm{Ba}, \mathrm{Ta}, \mathrm{W}$, and $\mathrm{Pb}$ ). Together with element intensities, we used the coherent and incoherent $X$-ray scattering of the atoms $13 \leq Z \leq 82$ of the Mo X-ray tube system. Of the detected elements, eight high-abundance and moderately to highly detectable (higher counts and lower RSD\%, Figure 4) elements, such as $\mathrm{Sr}, \mathrm{Br}, \mathrm{Fe}, \mathrm{Mn}, \mathrm{Ti}, \mathrm{Ca}, \mathrm{K}$, and $\mathrm{Cl}$ were detected at $1 \mathrm{~cm}$ resolution, and the total counts (cps) and coherent (coh) and incoherent (inc) X-ray scattering were selected for further data processing and interpretation. The elemental composition of the measured sediment sample was expressed as the intensity count per second (cps).

\subsubsection{Preparation of Calibration Curve for WD-XRF Concentration Measurement}

For the preparation of the calibration curve for WD-XRF concentration measurement, we used pressed pellet samples from different certified reference materials (CRMs). After being oven-dried $\left(50^{\circ} \mathrm{C}\right.$ at $\left.1 \mathrm{~h}\right), 4 \mathrm{~g}$ of the ground samples were mixed with $0.4 \mathrm{~g}$ (10:1) of Spectro Blend (Cat\# 3399N064, Spectro Blend CH660) binder. A set of dies was imposed at $120 \mathrm{kN}$ pressure with high-pressure equipment (Riken equipment Co., Ltd., Tokyo, Japan) that was equipped with a pressure gauge on a $40 \mathrm{~mm}$ diameter sample cup filled with a powder sample to make the pressed pellet [27]. In every step of sample preparation, high care was taken to avoid contamination.

Twelve (12) different CRMs (JA-1, JB-1a, JB-2, JB-3, JF-1, JG-3, JGb-1, JP-1, JR-1, JLK1, and JSd-2 from Geological Survey of Japan (GSJ), Tsukuba, Japan, and MESS-4 from National Research Council Canada (NRCC), Ottawa, ON, Canada) were used to construct a calibration curve. The published certified values of the target elements of these CRMs 
samples were $0.00033-0.0442,0.06-10.53,0.001-0.1817,0.0021-0.960,0.39-8.50$, and $0.002-$ 8.290 (wt\%) for Sr, Fe, Mn, Ti, Ca, and K, respectively. The calibration curve was used for the quantitative analysis of each element prepared through the Empirical Calibration (EC) method. The EC method is the method for calculating the concentration in samples based on the external calibration regression. The external calibration regression can be made by the relationship between the measured intensities of the fluorescence $X$-ray and the concentration that was obtained from standard samples similar to the unknown samples and intensities of the fluorescence X-ray of the unknown sample to perform the quantitative measurement. The operational flow (steps) for the quantitative measurement through the EC method are the creation of application file, setting of application information, standard samples, analysis information, and measuring condition, measurement of standard samples, calculation of regression, and setting of the control information.

Through different setup conditions (Table 1), and the setting of regression formulae, the background subtraction, drift correction, and matrix/overleap correction methods for smoothing the calibration curve were implemented.

Table 1. Measuring conditions for the selective elements of interest measured by Wavelength Dispersive X-ray Fluorescence (WD-XRF) Supermini 200 spectrometer.

\begin{tabular}{|c|c|c|c|c|c|c|c|c|}
\hline Element & $\begin{array}{l}\text { Analyte } \\
\text { Line }\end{array}$ & $\begin{array}{l}\text { Peak Mea- } \\
\text { surement } \\
\text { Angle }(2 \theta)\end{array}$ & Time (s) & Detector & PHA & Crystal & $\begin{array}{c}\text { Voltage } \\
(\mathbf{k V})\end{array}$ & $\begin{array}{c}\text { Current } \\
\text { (mA) }\end{array}$ \\
\hline $\mathrm{Sr}$ & $\mathrm{K} \alpha$ & 25.130 & 20 & $\mathrm{SC}^{1}$ & $100-300$ & $\operatorname{LiF}(200)$ & 50 & 4.00 \\
\hline $\mathrm{Fe}$ & $\mathrm{K} \alpha$ & 57.470 & 20 & $\mathrm{SC}$ & $100-350$ & $\operatorname{LiF}(200)$ & 50 & 4.00 \\
\hline $\mathrm{Mn}$ & $\mathrm{K} \alpha$ & 62.952 & 20 & SC & $100-350$ & $\operatorname{LiF}(200)$ & 50 & 4.00 \\
\hline $\mathrm{Ti}$ & $\mathrm{K} \alpha$ & 86.110 & 20 & SC & $50-300$ & $\operatorname{LiF}(200)$ & 50 & 4.00 \\
\hline $\mathrm{Ca}$ & $\mathrm{K} \alpha$ & 45.176 & 40 & $\mathrm{PC}^{2}$ & $100-300$ & PET & 50 & 4.00 \\
\hline K & $\mathrm{K} \alpha$ & 50.150 & 40 & PC & $100-300$ & PET & 50 & 4.00 \\
\hline
\end{tabular}

${ }^{1}$ SC-Scintillation Counter; ${ }^{2}$ PC-Proportional Counter.

\subsubsection{Validation of Calibration Method}

To check the validation of the calibration curve that was prepared through the Empirical Calibration method, a sample with known concentration was analyzed. Here, we used JA-3 certified reference material sample from the geological survey of Japan. For the preparation of the pressed pellet, an oven-dried sample (JA-3) was used. The sample preparation was the same as described in the above section (See Section 2.3.3). The analytical uncertainty (percent relative standard deviation (RSD $\%)$ ) of the reproduced $(n=7)$ measurements was less than $1 \%$ for all elements $(\mathrm{K}, \mathrm{Ca}, \mathrm{Ti}, \mathrm{Mn}, \mathrm{Fe}$, and $\mathrm{Sr})$. The percent relative standard deviation is expressed as $\operatorname{RSD} \%=((\sigma / \mu) \times 100)$, being same as the Equation (1) [24].

According to the guidelines of the international union of pure and applied chemistry (IUPAC), the detection limit $\left(\mathrm{L}_{\mathrm{D}}\right)$ and the quantification limit $\left(\mathrm{L}_{\mathrm{Q}}\right)$ were calculated based on the following Equations, respectively [28,29]:

$$
\begin{aligned}
& \mathrm{L}_{\mathrm{D}}=3.29 * \mathrm{~s} \\
& \mathrm{~L}_{\mathrm{Q}}=10 * \mathrm{~s}
\end{aligned}
$$

where $s$ is the standard deviation of the reproduced measurements. In the case of quantification limit the values ten times the standard deviation. Table 2 presents the calculated values of the $L_{D}$ and $L_{Q}$ based on Equations (2) and (3). 
Table 2. The detection limit $\left(\mathrm{L}_{\mathrm{D}}\right)$ and quantification limit $\left(\mathrm{L}_{\mathrm{Q}}\right)$ of the elements measured by WD-XRF spectrometer from the replicate measurements $(n=7)$ of the sample JA-3 according to Equations (2) and (3).

\begin{tabular}{ccc}
\hline Element & $\mathbf{L}_{\mathbf{D}} \mathbf{( w \mathbf { t } \% )}$ & $\mathbf{L}_{\mathbf{Q}}(\mathbf{w t} \mathbf{0})$ \\
\hline $\mathrm{K}$ & 0.01 & 0.02 \\
$\mathrm{Ca}$ & 0.03 & 0.10 \\
$\mathrm{Ti}$ & 0.01 & 0.02 \\
$\mathrm{Mn}$ & 0.003 & 0.01 \\
$\mathrm{Fe}$ & 0.03 & 0.10 \\
$\mathrm{Sr}$ & 0.0 & 0.0 \\
\hline
\end{tabular}

Replicate measurements $(n=7)$ of the standard sample (JA-3) confirmed that there was no significant difference $\left(\Delta_{\mathrm{m}} \leq \mathrm{U}_{\Delta}\right)$ between the measured and reference value of the target elements (Table 3). The values of $\Delta_{\mathrm{m}}$ and $\mathrm{U}_{\Delta}$ are obtained from the following expression $[29,30]$ :

$$
\Delta_{\mathrm{m}}=\left|\mathrm{C}_{\mathrm{m}}-\mathrm{C}_{\text {known }}\right|
$$

where $\Delta_{\mathrm{m}}$ indicates the absolute difference between the mean measured and certified (known) value, $C_{m}$ indicates the measured mean value, and $C_{\text {known }}$ indicates the certified (known) value. However, both of the measurements have an uncertainty; therefore, the combined uncertainty of $\Delta_{\mathrm{m}}$ is expressed as $\mathrm{u}_{\Delta}$ by the following formula:

$$
\mathrm{u}_{\Delta}=\sqrt{ }\left(\mathrm{u}^{2} \mathrm{~m}+\mathrm{u}^{2}{ }_{\text {known }}\right)
$$

where $u_{\Delta}$ is the combined uncertainty of the measured and certified value (known) that is the uncertainty of $\Delta_{\mathrm{m}}, \mathrm{u}_{\mathrm{m}}$ and $\mathrm{u}_{\text {known }}$ is the uncertainty of the measured value, and the certified (known) value, respectively. Finally, the expanded uncertainty $\left(\mathrm{U}_{\Delta}\right)$ is calculated by multiplying the combined uncertainty $\left(\mathrm{u}_{\Delta}\right)$ by a coverage factor $(\mathrm{k})$. The value of $\mathrm{k}$ is usually equal to 2 , which corresponds to a confidence level of approximately $95 \%$. Thus, expressed as:

$$
\mathrm{U}_{\Delta}=2 \mathrm{u}_{\Delta}
$$

Table 3. Comparison of the results obtained from the WD-XRF measurements with the certified reference value for the standard sample (JA-3) to determine the validation of the prepared calibration method.

\begin{tabular}{ccccc}
\hline Element (wt\%) & $\begin{array}{c}\text { Certified Value } \\
\text { (Mean } \pm \text { SD) }\end{array}$ & $\begin{array}{c}\text { Value Measured by } \\
\text { WD-XRF (Mean } \pm \text { SD) }\end{array}$ & $\boldsymbol{\Delta}_{\mathbf{m}}$ & $\mathbf{U}_{\boldsymbol{\Delta}}$ \\
\hline $\mathrm{K}_{2} \mathrm{O}$ & $1.41 \pm 0.06$ & $1.32 \pm 0.003$ & -0.090 & 0.120 \\
$\mathrm{CaO}$ & $6.24 \pm 0.16$ & $6.56 \pm 0.014$ & 0.318 & 0.321 \\
$\mathrm{TiO}_{2}$ & $0.70 \pm 0.06$ & $0.69 \pm 0.004$ & -0.015 & 0.120 \\
$\mathrm{MnO}_{\mathrm{T}-\mathrm{Fe}_{2} \mathrm{O}_{3}}$ & $6.104 \pm 0.01$ & $0.105 \pm 0.001$ & 0.001 & 0.02 \\
$\mathrm{Sr}^{\mathrm{b}}$ & $0.0287 \pm 0.18$ & $6.41 \pm 0.012$ & -0.194 & 0.361 \\
\hline
\end{tabular}

a Terashima et al., 1994 [31] and Guevara et al., 2005 [32]. ${ }^{\mathrm{b}}$ Imai et al., 1995 [33].

Finally, the method performance was evaluated by the comparison of $\Delta_{\mathrm{m}}$ with $\mathrm{U}_{\Delta}$, which is, if $\Delta_{\mathrm{m}} \leq \mathrm{U}_{\Delta}$, then there is no significant difference between the measurement value and the certified (known) value of the analyzed sample.

The good agreement between the measured and certified value, low detection limit, and low uncertainty from reproduced measurement confirm that the method of calibration of WD-XRF for measurement worked well. In every step, like during oven-dried of the sample, sample mixing with the binder, making pressed pellets, and during measurement, we were very careful to avoid contamination. 


\subsubsection{Measurement of Element Concentration through WD-XRF Spectrometer}

In addition to the ITRAX-XRF core scanning results, the quantitative concentrations of the selected elements (high abundance and being suitable for conventional XRF measurement), namely $\mathrm{Sr}, \mathrm{Fe}, \mathrm{Mn}, \mathrm{Ti}, \mathrm{Ca}$, and $\mathrm{K}$ (Figure 5), were measured using a Wavelength Dispersive X-ray Fluorescence (Rigaku Supermini 200) spectrometer, at the University of Toyama, Japan. To confirm the reliability of ITRAX-XRF CS element count data, we prepared thirty-three discrete bulk sediment samples from the working half. These discrete bulk sediment samples were selected from the basis of significant minima, maxima, and changeover intervals that were indicated by the ITRAX-XRF CS records. The selection of discrete samples also covered all the sections and climate events, such as Heinrich Stadial 1 (HS1), Bølling-Allerød (B-A), Younger Dryas (YD), Preboreal (PB), and Holocene intervals, being demarked after the determination of age through the construction of the age-depth model [34]. For the measurement of concentration, the freeze-dried discrete samples were ground to a particle size $<63 \mu \mathrm{m}$. The preparation of the sample for making pressed pellets for the measurement of element concentration the same as described in the above section (See Section 2.3.3). Afterward, the pressed pellets sample concentration was measured by using the prepared calibration curve (discuss in the Sections 2.3.3 and 2.3.4).

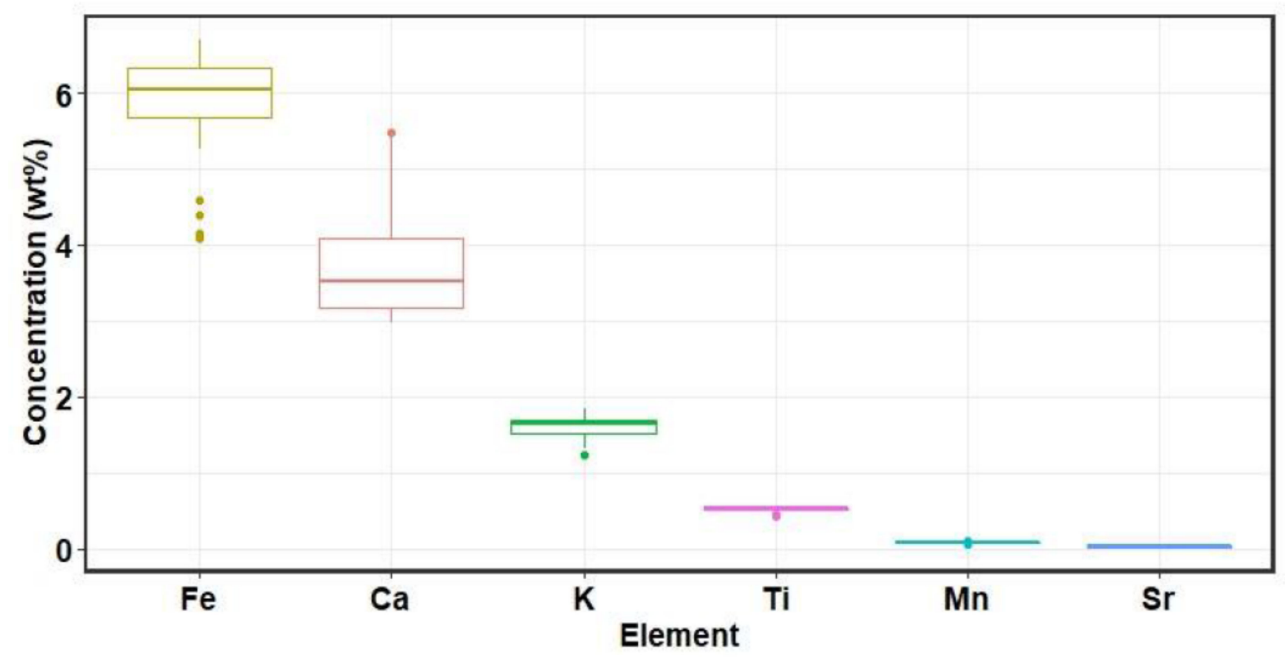

Figure 5. Boxplots of high abundance element determined by the conventional wavelength dispersive X-ray fluorescence (WD-XRF, Rigaku Supermini 200) spectrometer from the discrete bulk sediment samples of the core CL14PC plotted concentration ( $w \mathrm{t} \%$ ) versus elements $(\mathrm{Sr}, \mathrm{Fe}, \mathrm{Mn}, \mathrm{Ti}, \mathrm{Ca}$, and $\mathrm{K}$ ) in the $\mathrm{y}$ - and $\mathrm{x}$-axis, respectively. The outlier of each of the elements is indicated by the point shape.

\subsection{Total Organic Carbon Analysis}

The total organic carbon (TOC) was measured in the decarbonated bulk sediment sample of the core CL14PC. For this purpose, a total of 100 homogenized dried bulk ground sediments samples of $\sim 200 \mathrm{mg}$ each were decarbonated by adding $10 \mathrm{~mL}$ of $1 \mathrm{M} \mathrm{HCl}$ for each sample. Until the complete removal of the $\mathrm{CO}_{2}$ bubbles, the samples were kept at room temperature, and were centrifuged at 3000 rotations per minute (rpm) for $10 \mathrm{~min}$, and the supernatant was then discarded. After being rinsed three times with ultrapure water $(18.2 \mathrm{M} \Omega \cdot \mathrm{cm})$, the samples were completely oven-dried at $50{ }^{\circ} \mathrm{C}$ (overnight). The TOC measurement was accomplished at the University of Toyama, Japan by using an elemental analyzer (Vario EL cube CHNOS). The total carbon (TC) and total nitrogen (TN) were measured from the dried bulk sediment using the same facility. For calibration, sulfanilamide $\left(\mathrm{C}_{6} \mathrm{H}_{8} \mathrm{~N}_{2} \mathrm{O}_{2} \mathrm{~S}\right)$ was used as a standard. The replicate measurements $(n=4)$ of the TOC samples had an RSD of $1.6 \%$. 


\subsection{XRF Core Scanner Data Calibration}

The variation of down-core physical properties and matrix effects affect XRF core scanner measurement and reduce the integrity of scanning [4]. Therefore, the calibration (normalization) of XRF CS data is required to minimize the influence due to the matrix or specimen effects or closed-sum effects. In this study, we applied several techniques/approaches for the calibration of raw counts (cps) data, such as calibration by $X$-ray scattering, element ratio, total count (cps), and log-ratio transformation $[2,8,9]$. We categorized all of these approaches into two broad groups (methods), such as calibration by ratios (See Section 2.5.1) and log-ratio transformation (See Section 2.5.2). According to these methods, we normalized the XRF CS raw count (cps) data, thereafter, making a comparison based on their correlation with conventionally measured concentration.

A linear formula (Equation) was used to compare the conventional WD-XRF (wt $\%$ ) measurement concentration with ITRAX-XRF CS values (cps), as:

$$
\mathrm{W}_{i j}=a_{i}+\mathrm{I}_{i j} b_{i}
$$

where $\mathrm{W}_{i j}$ is the concentration (weight) that is measured by WD-XRF (wt\%) of element $i$ at depth $j, \mathrm{I}_{i j}$ is the intensity (cps) measured by the ITRAX-XRF CS of element $i$ at depth $j, a_{i}$ is the y-intercept of element $i$, and $b_{i}$ represents the slope of the regression line for element $i$.

\subsubsection{Calibration by Ratios}

One of the approaches for minimizing the potential complication/influence that is caused by the variation of the core physical properties or heterogeneities is the calibration of raw data by using different variables ratios. Thus, calibrated data may increase the correlation with their actual concentration when compared to raw data. We normalize the raw data through the application of different approaches under this category, afterward compare the calibrated data with concentration (Table A1). The variables that were used to normalize the raw cps data were expressed as:

$$
\begin{aligned}
& \text { Calibrated intensity }\left(\mathrm{I}_{i j}\right)=\text { raw intensity }\left(\mathrm{I}_{i j}\right) / \mathrm{XS}_{j} \\
& \text { Calibrated intensity }\left(\mathrm{I}_{i j}\right)=\text { raw intensity }\left(\mathrm{I}_{i j}\right) / \mathrm{TC}_{j} \\
& \text { Calibrated intensity }\left(\mathrm{I}_{i j}\right)=\text { raw intensity }\left(\mathrm{I}_{i j}\right) / \mathrm{EI}_{j}
\end{aligned}
$$

where $\mathrm{I}_{i j}$ is the intensity (cps) measured by the ITRAX-XRF CS of element $i$ at depth $j$, and $\mathrm{XS}_{j}$ in Equation (8) is the X-ray scattering at depth $j$. For X-ray scattering, we used the coherent/incoherent (coh/inc) X-ray scatter ratio (CIR), incoherent/coherent (inc/coh) $X$-ray scatter ratio (ICR), coherent $X$-ray scattering (coh), and the incoherent plus coherent (inc + coh) X-ray scattering $(\mathrm{I}+\mathrm{C})$. The $\mathrm{TC}_{j}$ shown in Equation (9) means the total count (TC) per second (total cps) at depth ${ }_{j}$, and the $\mathrm{EI}_{j}$ in Equation (10) means the specific element intensity at depth ${ }_{j}$. For the normalization of raw intensities in this study, we used two elements' intensities (Ti and $\mathrm{Ca}$ ) as denominators in Equation (10).

\subsubsection{Log-Ratio Transformation}

The log-ratio transformation reduces the closed-sum effects and facilitates multivariate analysis [12]. Two types of log-ratio transformation of data were employed in this study, namely, the additive log-ratio (alr) and centered log-ratio (clr) transformation. These log-ratio data transformations were calculated based on the following two equations [9]:

$$
\begin{gathered}
\operatorname{alr}\left(\mathrm{I}_{i j}\right)=\ln \left(\left(\mathrm{I}_{i j}\right) / \mathrm{X}_{j}\right) \\
\operatorname{cr}\left(\mathrm{I}_{i j}\right)=\ln \left(\left(\mathrm{I}_{i j}\right) / \mathrm{gm}_{j}\right)
\end{gathered}
$$

where $\mathrm{I}_{i j}$ is the ITRAX-XRF CS intensities of element $i$ at depth $j$ and $X_{j}$ is the variables applied for calculation at depth $j$. We used CIR (coherent/incoherent) as the variable for raw intensities, and coh (coherent) as the variable for raw and CIR normalized intensities 
in Equation (11). In Equation (12), gm $_{j}$ indicates the geometric mean at depth $j$-for the calculation of centered log-ratio (clr), we used the geometric mean of the raw XRF data (mention as clr of raw data in Table A1). Besides, we also calculated clr by using the geometric mean of the coherent/incoherent X-ray scatter ratio (CIR) calibrated XRF data (mentioned as clr of CIR calibrated data in Table A1). For this, we made three groups of elements: (i) $\mathrm{Sr}, \mathrm{Fe}, \mathrm{Mn}, \mathrm{K}, \mathrm{Ca}$, and Ti that were transformed in clr for comparison with WD-XRF concentration, (ii) $\mathrm{Br}$ and $\mathrm{Cl}$ for comparison with $\mathrm{TOC}$, and (iii) $\mathrm{Br} / \mathrm{Cl}$ ratio and $\mathrm{Cl}$ for comparison with TOC. The log-ratio (clr and alr) data transformations were executed by using a compositional data package, CoDaPack 2.03.01 [35], and/or R base ggplot2 package robCompositions.

\section{Results}

\subsection{Raw X-ray Fluorescence Core Scanner Data}

We compared the relationship between the ITRAX-XRF CS intensities (cps) with WD-XRF measured concentration ( $w \mathrm{t} \%$ ) using two different methods-linear regression through Pearson's method and Kendall's tau $(\tau)$ (Table A1) method. Kendall's tau $(\tau)$ method was used to confirm (cross-check) the accuracy of the correlation that was measured by Pearson's method to avoid miscalculation. Therefore, hereafter, linear regression means that Pearson's method calculated linear correlation. Because $\mathrm{Br}$ and $\mathrm{Cl}$ are not elements analyzed by using WD-XRF, the $\mathrm{Br}$ and $\mathrm{Cl}$ intensities are, thus, excluded for comparison with WD-XRF measured concentration. On the other hand, because $\mathrm{Br}$ and TOC are both productivity proxies and are related to organic matter content [36-38], the ITRAX-XRF CS $\mathrm{Br}$ intensities were compared with TOC (wt\%) through linear $\left(\mathrm{R}^{2}\right)$ regression and Kendall's $\tau$ (Figure 6, Table A1). In this study, the ITRAX-XRF CS raw cps data from the sediment core CL14PC were used as a baseline for comparison with different calibration methods.

The concentration $(\mathrm{w} \%)$ of the bulk sediment samples was measured using a WD-XRF spectrometer. Among the six elements $(\mathrm{Sr}, \mathrm{Fe}, \mathrm{Mn}, \mathrm{Ti}, \mathrm{Ca}$, and $\mathrm{K}), \mathrm{Fe}$ and $\mathrm{Ca}$ showed high concentrations-5.83 (wt \%) and $3.74(\mathrm{wt} \%)$, respectively (Figure 5). A comparison of the correlation of raw counts (cps) wth the WD-XRF measured concentration (wt\%) showed $0.31<R^{2}<0.84$ for linear regression $\left(R^{2}\right)$ and $0.38<\tau<0.79$ for Kendall's method. The coefficients of determination $\left(\mathrm{R}^{2}\right)$ of the measured elements, i.e., $\mathrm{Sr}, \mathrm{Fe}, \mathrm{Mn}, \mathrm{Ti}, \mathrm{Ca}$, and $\mathrm{K}$, were $0.84,0.84,0.51,0.31,0.72$, and 0.36 , respectively (Figure 6), in the raw data, showing less (weak) correlation for Ti and $\mathrm{K}$. In the case of $\mathrm{Br}$ and the $\mathrm{Br} / \mathrm{Cl}$ ratio, the correlations $\left(\mathrm{R}^{2}\right)$ between the raw intensities and TOC $(\%)$ were 0.72 and 0.64 , respectively, and, in Kendall's $\tau$, the values were 0.60 and 0.53 , respectively. In both cases $\left(R^{2}\right.$ and $\tau$ ), the relationship showed greater values in integral $\mathrm{Br}$ as compared to the $\mathrm{Br} / \mathrm{Cl}$ ratio (Figure 6, Table A1). 


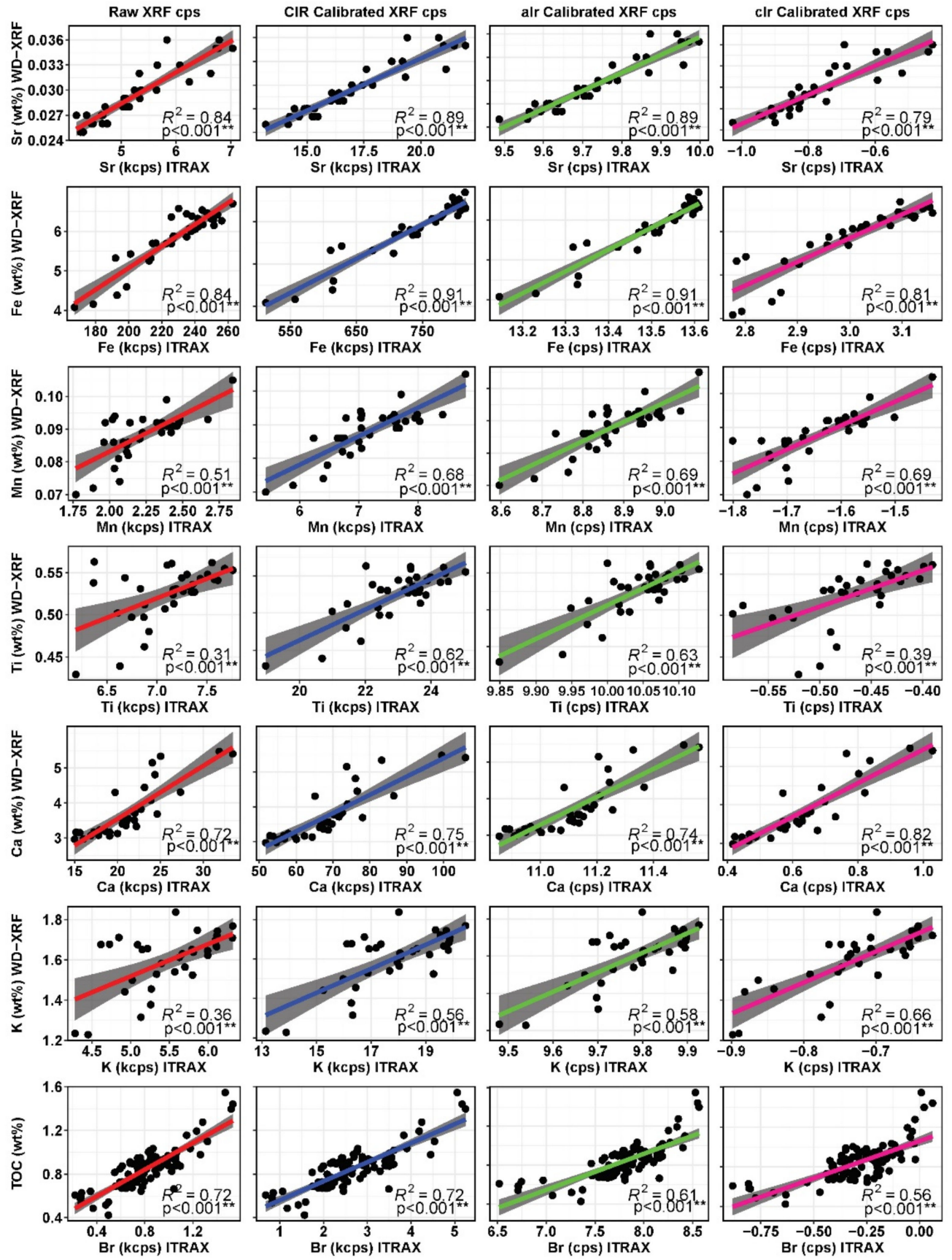

Figure 6. The comparison of correlation through linear regressions of ITRAX-XRF CS raw data (left side first column), and calibrated data by selected calibration approaches (from left to the right side) such as coherent/incoherent (coh/inc) X-ray scattering ratio (CIR), additive log-ratio transformation (alr) by Equation (11), and centered log-ratio transformation (clr) by Equation (12) with conventional WD XRF elemental concentrations (wt\%) for element $\mathrm{Sr}, \mathrm{Fe}, \mathrm{Mn}, \mathrm{Ti}, \mathrm{Ca}$, and $\mathrm{K}$, and the $\mathrm{Br}$ with TOC $(\%)$. The y-axis is common for each element for all the approaches. In the $x$-axis, cps means count per second and kcps means cps $\times 1000$. The regression lines of raw, and the CIR, alr, and clr calibrated data are presented by red, blue, green, and deep pink color, respectively, with a surrounded black shaded area represent $95 \%$ confidence interval of the regression lines.

\subsection{Calibrated X-ray Fluorescence Core Scanner Data}

In this study, we calibrated the raw count (cps) data into different procedures of two broad categories (group/method). The correlation $\left(R^{2}\right)$ of calibrated cps through different X-ray scattering ratios with WD-XRF concentrations and TOC (\%) were $0.56-0.91$ for coherent/incoherent X-ray scatter ratio (CIR) calibrated data, $0.07-0.77$ for incoherent/coherent 
X-ray scatter ratio (ICR) calibrated data, $0.05-0.74$ for coherent (coh) calibrated data, and 0.0-0.69 for incoherent + coherent calibrated data $(\mathrm{I}+\mathrm{C})$ (Table A1). The raw intensity (cps) that was normalized by total counts, $\mathrm{Ti}$, and $\mathrm{Ca}$ showed correlation $\left(\mathrm{R}^{2}\right)$ with conventional concentration (WD-XRF) of 0.0-0.81, 0.27-0.86, and 0.0-0.64, respectively (Table A1), under category ratio calibration. The log-ratio transformation of data (category log-ratio calibration) is an important procedure of XRF data calibration, as it reduces closed-sum effects, and it is suitable for multivariate statistics [9,12,39].

The centered log-ratio transformation using raw and coherent/incoherent $X$-ray scatter ratio (CIR) calibrated data showed the same correlation with concentration, and the range was 0.29-0.82 (Table A1). The additive log-ratio transformation by using CIR and coh as the denominator in the case of raw data in Equation (11) showed $\mathrm{R}^{2}$ values of 0.58-0.91, and 0.05-0.76, respectively, when correlating with WD-XRF concentration and TOC (here, $\mathrm{Br}$ and $\mathrm{Br} / \mathrm{Cl}$ compare with TOC) (Table A1). In the case of the coherent/incoherent X-ray scatter ratio, calibrated data transform in the additive log-ratio by using coherent (coh) X-ray scatter, as the denominator in Equation (11) showed $\mathrm{R}^{2}$ values of $0.30-0.82$ when compared with concentration and TOC\% (Table A1).

\section{Discussion}

\subsection{Sediment Physical Properties Affect Scanning Intensities}

In the sediment core, the top sediments are generally characterized by higher porewater contents that were expressed by high $\mathrm{Cl}$ content, especially in marine sediments, because $\mathrm{Cl}$ is a major dissolved element of seawater. In lacustrine and other freshwater sediments, the scenario is different, because lacustrine and freshwater sediments contain extremely low $\mathrm{Cl}$ content. The $\mathrm{XRF}$ intensity of $\mathrm{Cl}$ is used as a water content proxy for marine sediment [4]. The $\mathrm{Cl}$ intensity in the core CL14PC significant increases in the topmost part, especially in the upper $202 \mathrm{cmbsf}$ depth (Figure 7), suggesting high interstitial/porewater content. At depth $201 \mathrm{cmbsf}$, the $\mathrm{Cl}$ intensity (cps) increases 29\% from depth $202 \mathrm{cmbsf} \mathrm{Cl}$ cps, and, in the top $202 \mathrm{cmbsf}$, the average $\mathrm{Cl}$ content (cps) increases $42 \%$ when compared to the down-core average $\mathrm{Cl}$ content (cps). In the core top, the high $\mathrm{Cl}$ intensity (cps), indicating high water content, influences X-ray scattering, and further influences element intensity measurement in the core. The $\mathrm{Cl}$ intensity also exhibits elevation in the down-core at 793-766 cmbsf depth.

The wet bulk density (gm/cc) at the top of the core from the depth 202 to $25 \mathrm{cmbsf}$ did not show extreme variation (Figure 7). However, at the top-most 25 cmbsf, the density sharply decreases from 1.82 to $1.03 \mathrm{gm} / \mathrm{cc}$, and the average $\mathrm{Cl}$ content increases $73 \%$ when compared to the down-core average $\mathrm{Cl}$ content below $202 \mathrm{cmbsf}$ depth. At the depth 766 to 737 and 716 to $676 \mathrm{cmbsf}$, the wet bulk density (gm/cc) was more prominently low (Figure 7). At that depth, the Br content (cps) was significantly high. Br has been used as a good proxy for marine organic matter and related productivity tracer in the ocean basins [36-38]. These high $\mathrm{Br}$ intensity intervals are characterized by organic-rich marine sediments (high TOC and low TOC/TN molar ratio) that are derived from marine algal sources with a dark area (seen in CT-scan photography in Figure 3) and low density. In that depth, the variation of the bulk density $(\mathrm{gm} / \mathrm{cc})$ inversely reflects the X-ray scattering. Although a lower sedimentary density at 766-737 and 716-676 cmbsf depth increases the $X$-ray scattering, with Compton (incoherent) scattering [40] being remarkably high, after correction, the pattern of variation of the element intensity (cps), especially Br and Ca (related to organic matter), did not significantly change (See Section 4.3). Thus, strengthening the water content is responsible for the deviation of the scanning intensity. Therefore, in this study, the coherent/incoherent $X$-ray scattering ratio calibration of raw intensity showed a high correlation with WD-XRF measured concentration. The coherent/incoherent scattering (inc/coh) ratio (CIR) is used for the calibration of raw intensity (cps), where water content has greater influence [5,8]. Meanwhile, some of the researchers have used X-ray scattering (incoherent/coherent ratio) for the correction of raw XRF counts when the organic matter has a greater influence $[15,16]$. 


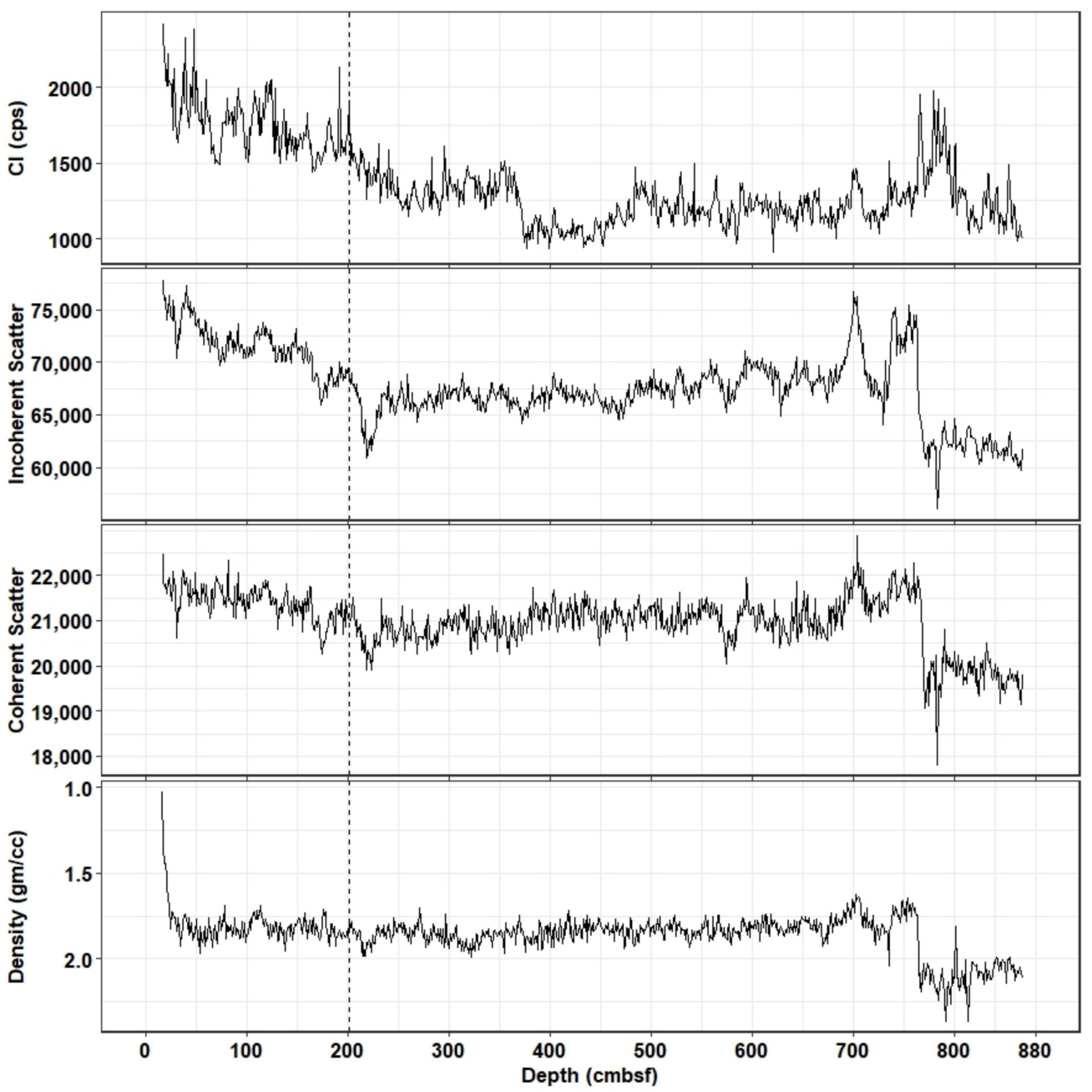

Figure 7. The wet bulk density ( $\mathrm{gm} / \mathrm{cc})$, X-ray scattering of incoherent and coherent, and $\mathrm{Cl}$ counts (cps) are plotted versus depth (cmbsf) of the core CL14PC. The vertical black dash line at $202 \mathrm{cmbsf}$ positions indicating the porewater $\mathrm{Cl}$ content increasing abruptly toward the core top.

\subsection{Element Intensities Calibration by Ratios}

The correlation $\left(\mathrm{R}^{2}\right)$ that was calculated between the raw counts and WD-XRF concentrations ( $w t \%)$ of lighter elements, especially Ti and $\mathrm{K}$, showed a weak relationship (Figures 6 and 8), and the scattering distance from the regression line increased (Figure 6). The ITRAX-XRF CS Cl counts exhibited increasing values toward the core-top, and, inversely, the $\mathrm{K}$ and Ti intensities decreased at the horizon. This might be a primary factor in artificially influencing element counts through inaccurate or imprecise detection throughout the core. In addition, a previous study [1] reported that the higher porewater content influences $\mathrm{K}$ by means of the absorption of the $\mathrm{K} \alpha$ fluorescence of $\mathrm{K}$ by seawater $\mathrm{Cl}$ atoms. Ti might also be influenced by higher porewater content [6], because porewater increases the looseness and decreases the compaction in sediments. Under ratio calibration methods, we calibrated the raw intensity data using coherent/incoherent $\mathrm{X}$-ray scatter ratio (CIR), incoherent/coherent $X$-ray scatter ratio (ICR), coherent $X$-ray scatters (coh), incoherent + coherent $\mathrm{X}$-ray scatter $(\mathrm{I}+\mathrm{C})$, total count $(\mathrm{cps}), \mathrm{Ti}$, and Ca element intensity. Among these approaches, the calibration of raw $\mathrm{K}$ intensity (cps) through Ca intensity and CIR yields the highest correlation, with WD-XRF concentrations of 0.63 and 0.56, respectively, in linear regression and 0.62 and 0.48 , respectively, for Kendall's $\tau$ (Table A1). We found the correlation $\left(R^{2}\right)$ values for $K$ and Ca to be slightly increased when being normalized by $\mathrm{Ca}$ and $\mathrm{Ti}$ intensities (element ratio), respectively, as compared to CIR normalization. The geochemically antipathetic behavior of Ca with respect to $\mathrm{K}$ or Ti [6] as the atomic 
numbers of K (19), Ca (20), and Ti (22) are nearly identical, enhanced the correlation with concentration. However, the element ratio calibration does not fully avoid artifacts due to porewater or matrix effects for other elements ( $\mathrm{Sr}, \mathrm{Fe}, \mathrm{Mn}, \mathrm{Ti}$, and $\mathrm{Br}$ ), because the X-ray attenuation due to matrix effects fluctuates with photon energy [5]. Therefore, the calibration of raw data through element ratios (here using $\mathrm{Ca}$ and $\mathrm{Ti}$ intensities as the denominator) did not provide a good result for all elements and diverged from correlation values that were found in the CIR calibration methods in this study. In the case of Ti, the CIR calibrated intensities showed greater correlation $\left(\mathrm{R}^{2}=0.62\right)$ with WD-XRF concentration as compared to raw data. For both elements (K and Ti), the correlation with WD-XRF concentration significantly increased in CIR calibrated data, for which Ti increased $100 \%$ and K increased $56 \%$ from raw correlation. Similarly, the calibration of raw intensity (cps) through CIR for the elements $\mathrm{Sr}, \mathrm{Fe}, \mathrm{Mn}$, and Ca showed a greater correlation with WD-XRF concentration when compared to other ratio calibration processes (approaches).

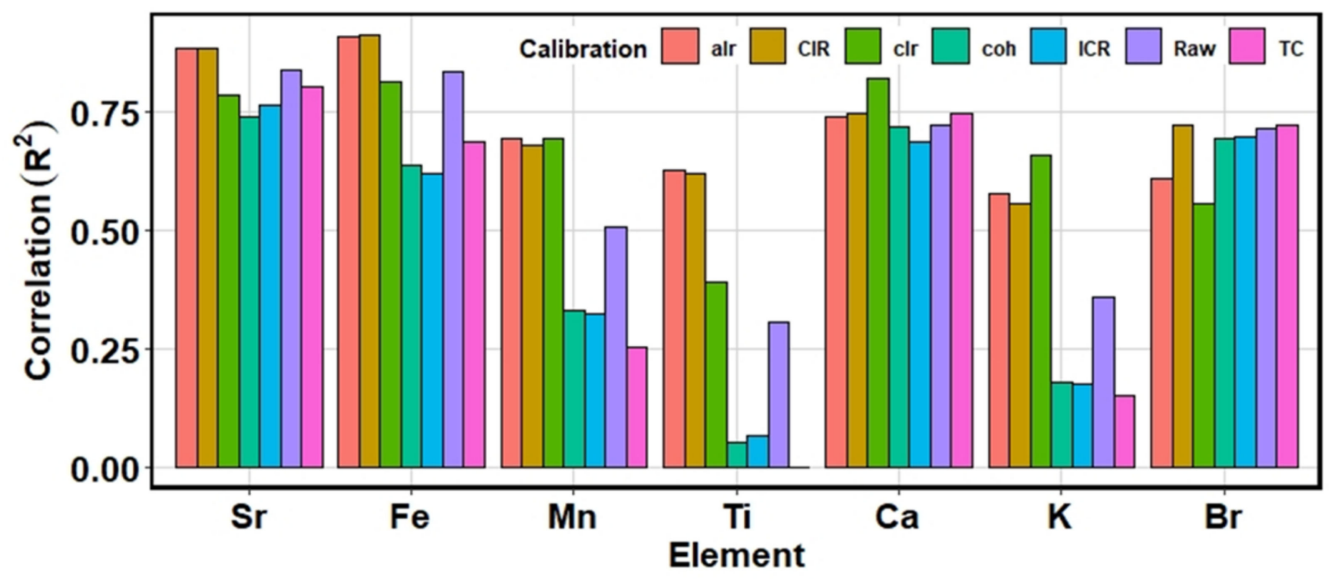

Figure 8. The coefficients of determination $\left(\mathrm{R}^{2}\right)$ calculated from ITRAX-XRF CS raw and calibrated (alr, CIR, clr, coh, ICR, and TC (total count)) data with conventional WD-XRF concentration are plotted in the y-axis and the elements in the $\mathrm{x}$-axis for comparison. Here, only presented the correlation $\left(R^{2}\right)$ results of six calibration approaches and raw data, for detail, see the text and Table A1.

The relationship between the $\mathrm{Br}$ count and TOC ( $\mathrm{wt} \%)$ presented a slight deviation in the uppermost part of the core CL14PC that was marked by an interval of high $\mathrm{Cl}$ (porewater) content. Because seawater $\mathrm{Br}$ sometimes overprints on algal $\mathrm{Br}$, the XRF $\mathrm{Br}$ count intensities are sometimes normalized by $\mathrm{Cl}$ counts. Although the $\mathrm{Br} / \mathrm{Cl}$ ratio seems to work as a good tracer with TOC in the upper part of the core, it does not have good agreement with TOC variation in the downcore trends of the core and it has a lower correlation with TOC $\left(\mathrm{R}^{2}=0.64, n=100\right)$ when compared to integral $\mathrm{Br}$ (Table A1). However, the correlation of CIR-calibrated Br intensities $\left(R^{2}=0.7215\right)$ showed a very minor increase or almost similar values compared to raw correlation $\left(R^{2}=0.7156\right)$ (Figure 6). This heavier $(Z=35)$, high-atomic weight $(80)$, and high-excitation $(\mathrm{K} \alpha=11.9 \mathrm{keV})$ energy element $[36,41]$ is relatively unaffected, and, in most cases, the magnitude of $\mathrm{Br}$ cps in CIR calibration increases or decreases proportionately with the relation of raw cps variation.

\subsection{Element Intensities Calibration by Log-Ratios}

For the raw and CIR calibrated cps, when transformed through centered log-ratio (clr), the geometric mean varies in a similar proportion and after transformation, thus making similar values in both cases. Therefore, when compared with concentration (WD-XRF), we found similar correlation values (Table A1). However, exceptions occur when $\mathrm{Br} / \mathrm{Cl}$ raw data and the $\mathrm{Br} / \mathrm{Cl} \mathrm{CIR}$ ratio were separately transformed with $\mathrm{Cl}$ through clr-they make different geometric means and, furthermore, different calibrated intensities (cps). Therefore, the CIR-calibrated clr Br/Cl ratio data $\left(R^{2}=0.29\right)$ and raw clr Br/Cl ratio data $\left(R^{2}=0.34\right)$ have different correlations with concentration (TOC) (Table A1). The correlation $\left(R^{2}\right)$ values 
for $\mathrm{Ti}, \mathrm{K}$, and $\mathrm{Mn}$ were $0.39,0.66$, and 0.69 , respectively, (Table A1) in the clr approach. The $\mathrm{R}^{2}$ value in the case of $\mathrm{K}$ slightly increases in the clr log-ratio transformation method, but, in $\mathrm{Ti}$, the value significantly decreases when compared to the CIR ratio calibration discussed in the above section (See Section 4.2). The correlation between clr calibrated intensity with concentration (WD-XRF and TOC) for $\mathrm{Sr}, \mathrm{Fe}, \mathrm{Ca}$, and $\mathrm{Br}$ was 0.79, 0.81, 0.82, and 0.56, respectively. Although Lee [9] suggested that the calibration of data through clr transformation was best when compared to alr transformation and ratio calibration in lacustrine (lake) sediment, our marine-based sediment from northeastern GOA did not show the best performance in the clr transformation method as compared to the CIR and alr approaches, suggesting that the calibration of XRF data is not method-specific-it may vary according to sediment samples, sample condition, region, and/or depend on the scanning instrument.

In the additive log-ratio calibration approach $[9,12]$, when the raw cps was transformed by using the CIR (coh/inc) ratio as the denominator, the values showed a good correlation with concentration (WD-XRF and TOC) (Table A1). The correlation $\left(\mathrm{R}^{2}\right)$ with concentration (WD-XRF and TOC) for Sr, Fe, Mn, Ti, Ca, K, and Br was 0.89, 0.91, 0.69, 0.63, 0.74, 0.58, and 0.61 , respectively. Although the relationship between ITRAX-XRF CS intensities and WD-XRF concentration through the alr and CIR calibration approach showed almost similar values for the elements $\mathrm{Sr}, \mathrm{Fe}, \mathrm{Mn}, \mathrm{Ti}, \mathrm{Ca}$, and $\mathrm{K}$, different results were found for the $\mathrm{Br}$ intensities when compared with TOC. The relationship between $\mathrm{Br}$ intensities and TOC increased 0.11 in the CIR calibrated data as compared to the alr log-ratio calibrated data. However, the goodness of fit for additive log-ratio depends on which parameters or elements are used as the denominator for data transformation. The wrong selection significantly influences the actual agreement.

However, the relationship (correlation) between ITRAX-XRF CS data and the concentration that was measured by conventional WD-XRF in the CIR ratio calibration method shows good agreement [8], and the values were increased from the values of the raw relationship in all of the selected elements $(\mathrm{Sr}, \mathrm{Fe}, \mathrm{Mn}, \mathrm{Ti}, \mathrm{Ca}, \mathrm{K}$, and $\mathrm{Br}$ ) in this study (Figure 6 and Table A1). The coefficient of determination of all the elements was above $0.50\left(\mathrm{R}^{2}>0.50\right)$ in the CIR calibrated data using the ratio method, of which the values of lighter elements (Mn, Ti, K) improved significantly from raw values (Figure 9), although Tjallingii [4] mentioned that $\mathrm{K}$ and Ti were relatively unaffected by the variation of core physical properties (water content). The relationship that was measured by Kendall's tau $(\tau)$ method also showed a positive correlation ( $\tau$ correlation) of all the elements that were higher than the raw data $\tau$ correlation (Table A1).

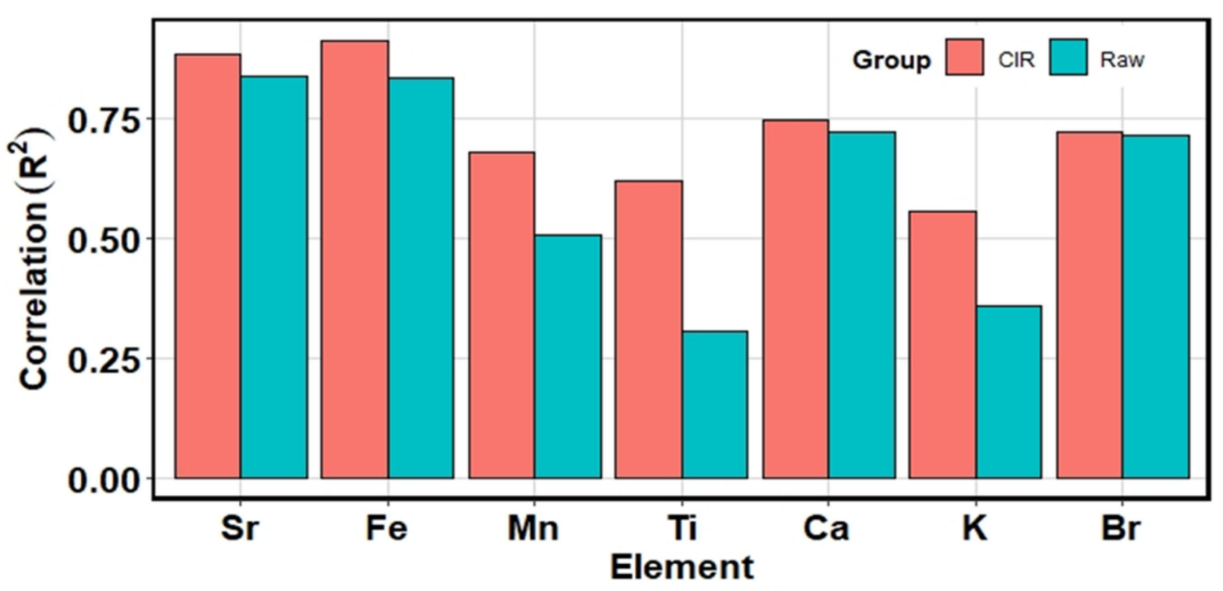

Figure 9. The comparison of correlation $\left(\mathrm{R}^{2}\right)$ determined from ITRAX-XRF CS raw data and the CIR calibrated data versus WD-XRF concentration by a linear regression method. In the case of $\mathrm{Br}$, the correlation was determined between $\mathrm{Br}$ versus TOC ( $\mathrm{wt} \%)$. The measured coefficient of determinations $\left(\mathrm{R}^{2}\right)$ plotted versus different elements $(\mathrm{Sr}, \mathrm{Fe}, \mathrm{Mn}, \mathrm{Ti}, \mathrm{Ca}, \mathrm{K}$, and $\mathrm{Br}$ ) in the $\mathrm{x}$-axis. 
Therefore, from the above evaluation, we can conclude that the raw cps that was calibrated by coherent/incoherent X-ray scatter (coh/inc) ratio (CIR) (ratio calibration method) is the best fit for the calibration or normalization of X-ray fluorescence scanning data. Based on this result, we, therefore, applied the coh/inc ratio (CIR) for the calibration of the entire raw cps data (Figure 10, violet color) of the core CL14PC. In the calibrated data, the element intensity (cps) was rescaled when compared to raw cps, and the relative magnitude of the minima and maxima was changed. In the upper part, the calibrated cps showed a substantially higher magnitude of increase relative to raw cps, particularly for $\mathrm{Sr}$, $\mathrm{Fe}, \mathrm{Mn}, \mathrm{Ti}$, and $\mathrm{K}$ (Figure 10), where the $\mathrm{Cl}$ XRF intensity (cps) was higher. The down-core profile for almost all of the elements studied in this experiment showed a high or low scale of magnitude when compared to the raw intensity (cps) variation.

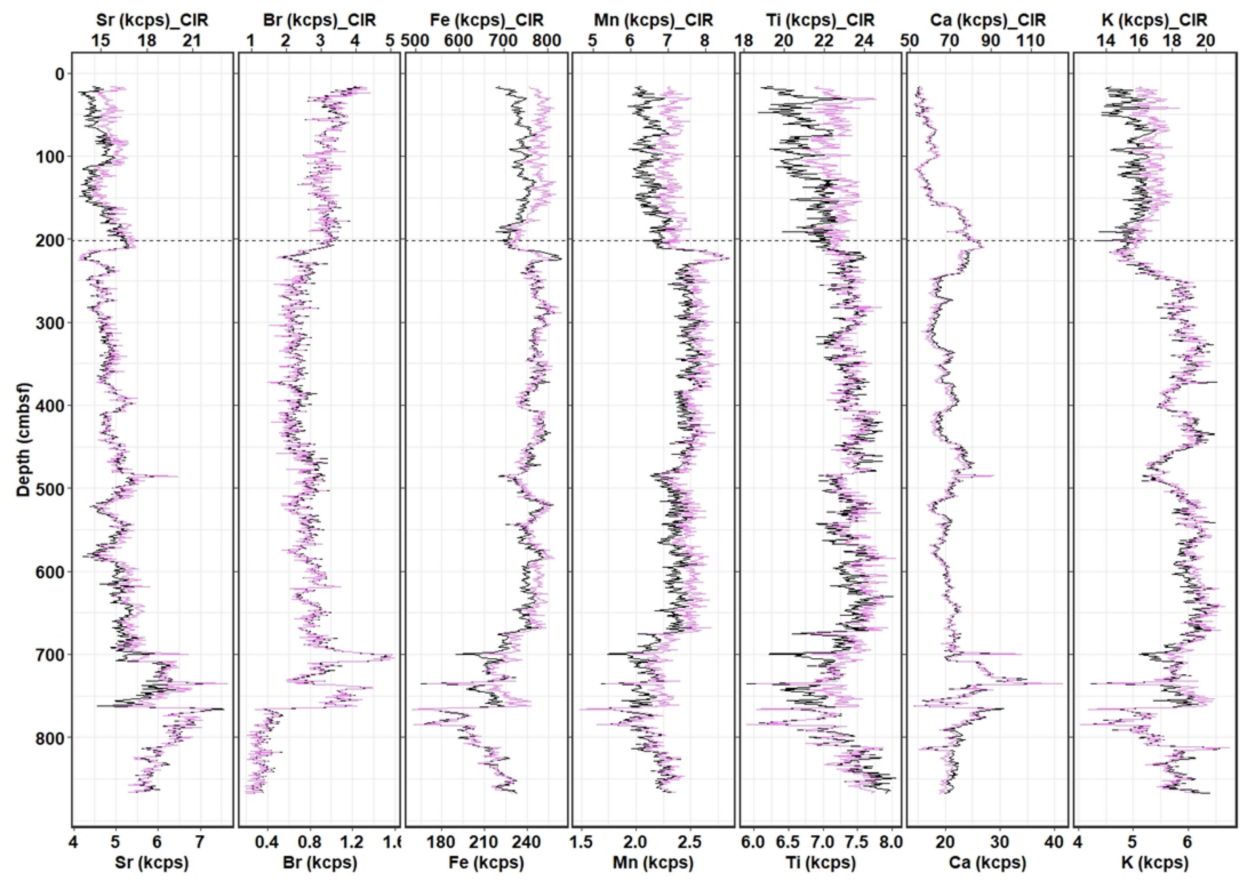

Figure 10. The corrected intensity (kcps, violet color) through the CIR calibration and the raw intensity (kcps, black color) from ITRAX-XRF CS count for the element $\mathrm{Sr}, \mathrm{Br}, \mathrm{Fe}, \mathrm{Mn}, \mathrm{Ti}, \mathrm{Ca}$, and $\mathrm{K}$ is plotted versus core depth in centimeter below seafloor scale (cmbsf). The black dash line at $202 \mathrm{cmbsf}$ indicating the demarcation of the high porewater influence in the core top. Here, $\mathrm{kcps}=\mathrm{cps} * 1000$.

\section{Conclusions}

In this study, we ran the ITRAX X-ray fluorescence core scanner by using a Molybdenum (Mo) X-ray anode tube at a $30 \mathrm{kV}$ voltage and $55 \mathrm{~mA}$ current with a 20-s exposure time for the scanning of a wet marine sediment piston core that was collected from the Northeastern Gulf of Alaska continental slope. The ITRAX provides high counts (cps) for the elements $\mathrm{Sr}, \mathrm{Fe}, \mathrm{Mn}, \mathrm{Ti}, \mathrm{Ca}, \mathrm{K}, \mathrm{Br}$, and $\mathrm{Cl}$, with relatively low $\mathrm{RSD}(\%)$. The $\mathrm{Cl}$ intensity increases toward the top of the core, with an average increase of $42 \%$ as compared to the down-core average cps (the dividing point at depth $202 \mathrm{cmbsf}$ ). In the down-core, at the depth 793-766 cm below the seafloor, the $\mathrm{Cl}$ content also exhibited elevated values. The high $\mathrm{Cl}$ content indicated high seawater content, because, in marine sediments, the XRF Cl intensity is expressed as the seawater content. Thus, this significantly affects the correlation between raw counts and concentration measured by WD-XRF spectrometer, especially the lighter elements (K and Ti), which are affected greatly. In this study, we compile several normalization processes under two calibration methods-ratio and log-ratio-that have been sporadically applied in different research works. Therefore, in the future, relevant researchers can utilize these multiple approaches to test their multi-sensor datasets and 
find the best method of correction for their datasets. However, we tested these multiple techniques in our sediment core to find out the best method for the normalization of the raw intensity data that eliminates the effects and provides the highest accuracy from raw counts. Among the calibration approaches, the correction of the raw cps by coherent/incoherent (coh/inc) X-ray scatter ratio (CIR) showed the best performance when correlating with concentration. The correlation that was measured through linear regression with Pearson's method and Kendall's tau $(\tau)$ method substantially increased in the CIR normalization using the ratio calibration method as compared to raw correlation. The correlation increased in lighter elements by $100 \%, 56 \%$, and $33 \%$ in Ti, K, and $\mathrm{Mn}$, respectively, when compared to raw correlation. Therefore, based on our evaluation, we can conclude that the normalization of ITRAX-XRF CS raw data by coherent to incoherent X-ray scatter ratio (CIR) can be applied for marine-based sediments to obtain good multi-elemental records through minimizing the effects due to the core physical properties and, thus, may further increase the reliability of using XRF core scanning data.

Author Contributions: Conceptualization, M.N.M. and K.H.; methodology, M.N.M. and K.H.; software (CoDaPack Software 2.03.01 (2011), ggplot2 3.1.0 (December 2018), QGIS 3.16.1 (2020), R 4.0.3 (2020)), M.N.M. and K.H.; validation, M.N.M., K.H., O.S., K.N., H.M., M.M. and Y.O.; formal analysis, M.N.M. and K.N.; investigation, M.N.M., K.H., K.N. and M.M.; resources, K.H. and M.M.; data curation, M.N.M. and K.H.; writing — original draft preparation, M.N.M.; writing—review and editing, M.N.M., K.H., O.S., H.M., and Y.O.; visualization, M.N.M.; supervision, K.H., O.S., H.M., M.M. and Y.O.; project administration, K.H.; funding acquisition, K.H. All authors have read and agreed to the published version of the manuscript.

Funding: We thankfully acknowledge the funding support of this work by the Japan Society for the Promotion of Science (JSPS) under the program grants-in-aid for scientific research (KAKENHI, Grant \# JP17H01853).

Data Availability Statement: The datasets used and/or analyzed during the current study are available from the corresponding author on reasonable request.

Acknowledgments: We warmly acknowledge the Center for Advanced Marine Core Research, Kochi University, Japan for their facilities. The authors are grateful to Yasushi Ono, the University of Toyama for his contribution and facility during the time of elemental analysis. We provide our thanks to Hajime Obata, Koji Seike, onboard scientist, captain, and crew of the cruise R/V Hakuho-Maru KH17-3. We thank three anonymous reviewers for their thoughtful comments and suggestions that improved the manuscript. We thank the editor, editorial, and production team of the journal for their cooperation.

Conflicts of Interest: The authors declare that they have no known competing financial interests or personal relationships that could have appeared to influence the work reported in this paper. 


\section{Appendix A}

Table A1. The Pearson's ( $\mathrm{R}^{2}$, through equation (7)) and the Kendall's Tau $(\tau)$ correlations results between ITRAX-XRF CS raw, ratio and log-ratio corrected element intensity (cps) data and WD-XRF concentration (wt\%) results. $\mathrm{For} \mathrm{Br}$ and $\mathrm{Br} / \mathrm{Cl}$ ratio the correlation was calculated between ITRAX-XRF CS Br intensities (cps) and $\mathrm{Br} / \mathrm{Cl}$ ratio with TOC (wt $\%$ ).

\begin{tabular}{|c|c|c|c|c|c|c|c|c|c|c|}
\hline & & \multirow{3}{*}{$\begin{array}{l}\text { Correlation } \\
\text { Method }\end{array}$} & \multicolumn{8}{|c|}{$\begin{array}{l}\text { Correlation between ITRAX-XRF CS Intensities (cps) with WD-XRF Concentration ((wt\%), } \\
\qquad n=33) \text {, and TOC }\left(\left(w^{\mathrm{t}} \%\right), n=100\right)\end{array}$} \\
\hline \multirow{2}{*}{\multicolumn{2}{|c|}{ Category }} & & \multicolumn{8}{|c|}{ Element } \\
\hline & & & $\mathrm{Sr}$ & $\mathrm{Fe}$ & Mn & $\mathrm{Ti}$ & $\mathrm{Ca}$ & K & Brv TOC & $\begin{array}{c}\mathrm{Br} / \mathrm{Cl} \mathrm{v} \\
\text { TOC }\end{array}$ \\
\hline \multirow{2}{*}{\multicolumn{2}{|c|}{ Raw XRF CS }} & Pearson $\left(\mathrm{R}^{2}\right)$ & 0.84 & 0.84 & 0.51 & 0.31 & 0.72 & 0.36 & 0.72 & 0.64 \\
\hline & & Kendall's $\tau$ & 0.79 & 0.66 & 0.47 & 0.38 & 0.71 & 0.41 & 0.60 & 0.53 \\
\hline \multirow{2}{*}{\multicolumn{2}{|c|}{$\mathrm{CIR}^{\mathrm{a}}$}} & Pearson $\left(\mathrm{R}^{2}\right)$ & 0.89 & 0.91 & 0.68 & 0.62 & 0.75 & 0.56 & 0.72 & 0.64 \\
\hline & & Kendall's $\tau$ & 0.83 & 0.78 & 0.55 & 0.45 & 0.73 & 0.48 & 0.61 & 0.53 \\
\hline \multirow{12}{*}{$\begin{array}{l}\text { Calibration } \\
\text { by ratio }\end{array}$} & \multirow{2}{*}{$\mathrm{ICR}^{\mathrm{b}}$} & Pearson $\left(\mathrm{R}^{2}\right)$ & 0.77 & 0.62 & 0.32 & 0.07 & 0.69 & 0.17 & 0.70 & 0.64 \\
\hline & & Kendall's $\tau$ & 0.73 & 0.55 & 0.38 & 0.29 & 0.68 & 0.30 & 0.59 & 0.53 \\
\hline & \multirow{2}{*}{$\operatorname{coh}^{c}$} & Pearson $\left(\mathrm{R}^{2}\right)$ & 0.74 & 0.64 & 0.33 & 0.05 & 0.72 & 0.18 & 0.70 & 0.64 \\
\hline & & Kendall's $\tau$ & 0.75 & 0.61 & 0.37 & 0.30 & 0.70 & 0.32 & 0.60 & 0.52 \\
\hline & \multirow{2}{*}{$\mathrm{I}+\mathrm{C}^{\mathrm{d}}$} & Pearson $\left(R^{2}\right)$ & 0.69 & 0.45 & 0.22 & 0.00 & 0.68 & 0.07 & 0.68 & 0.64 \\
\hline & & Kendall's $\tau$ & 0.67 & 0.53 & 0.29 & 0.18 & 0.66 & 0.24 & 0.59 & 0.53 \\
\hline & \multirow{2}{*}{ Total count (cps) } & Pearson $\left(\mathrm{R}^{2}\right)$ & 0.81 & 0.69 & 0.25 & 0.00 & 0.75 & 0.15 & 0.72 & 0.64 \\
\hline & & Kendall's $\tau$ & 0.77 & 0.57 & 0.27 & 0.09 & 0.71 & 0.30 & 0.61 & 0.52 \\
\hline & \multirow{2}{*}{ Ti intensity (cps) } & Pearson $\left(R^{2}\right)$ & 0.85 & 0.86 & 0.56 & & 0.82 & 0.27 & 0.65 & 0.64 \\
\hline & & Kendall's $\tau$ & 0.84 & 0.80 & 0.56 & & 0.75 & 0.32 & 0.57 & 0.52 \\
\hline & \multirow{2}{*}{ Ca intensity (cps) } & Pearson $\left(\mathrm{R}^{2}\right)$ & 0.00 & 0.64 & 0.51 & 0.46 & & 0.63 & 0.52 & 0.64 \\
\hline & & Kendall's $\tau$ & -0.09 & 0.74 & 0.67 & 0.57 & & 0.62 & 0.49 & 0.52 \\
\hline \multirow{10}{*}{$\begin{array}{l}\text { Calibration by } \\
\text { log-ratio }\end{array}$} & \multirow{2}{*}{$\begin{array}{l}\mathrm{clr}^{\mathrm{e}} \text { of CIR } \\
\text { calibrated data }\end{array}$} & Pearson $\left(R^{2}\right)$ & 0.79 & 0.81 & 0.69 & 0.39 & 0.82 & 0.66 & 0.56 & 0.29 \\
\hline & & Kendall's $\tau$ & 0.78 & 0.81 & 0.70 & 0.56 & 0.76 & 0.62 & 0.52 & 0.33 \\
\hline & \multirow{2}{*}{ clr of raw data } & Pearson $\left(R^{2}\right)$ & 0.79 & 0.81 & 0.69 & 0.39 & 0.82 & 0.66 & 0.56 & 0.34 \\
\hline & & Kendall's $\tau$ & 0.78 & 0.81 & 0.70 & 0.56 & 0.76 & 0.62 & 0.52 & 0.36 \\
\hline & \multirow{2}{*}{ alr ${ }^{f}$ by CIR } & Pearson $\left(\mathrm{R}^{2}\right)$ & 0.89 & 0.91 & 0.69 & 0.63 & 0.74 & 0.58 & 0.61 & 0.60 \\
\hline & & Kendall's $\tau$ & 0.82 & 0.79 & 0.58 & 0.45 & 0.74 & 0.48 & 0.61 & 0.55 \\
\hline & \multirow{2}{*}{$\begin{array}{l}\text { alr by coh after CIR } \\
\text { calibration }\end{array}$} & Pearson $\left(\mathrm{R}^{2}\right)$ & 0.82 & 0.82 & 0.52 & 0.30 & 0.74 & 0.40 & 0.58 & 0.52 \\
\hline & & Kendall's $\tau$ & 0.79 & 0.75 & 0.52 & 0.49 & 0.72 & 0.42 & 0.61 & 0.50 \\
\hline & \multirow{2}{*}{ alr by coh } & Pearson $\left(\mathrm{R}^{2}\right)$ & 0.76 & 0.66 & 0.32 & 0.05 & 0.67 & 0.17 & 0.59 & 0.52 \\
\hline & & Kendall's $\tau$ & 0.75 & 0.61 & 0.37 & 0.30 & 0.70 & 0.32 & 0.60 & 0.50 \\
\hline
\end{tabular}

${ }^{\mathrm{a}} \mathrm{CIR}=$ coherent/incoherent $\left(\mathrm{coh} /\right.$ inc) $\mathrm{X}$-ray scatter ratio; ${ }^{\mathrm{b}} \mathrm{ICR}=$ incoherent $/$ coherent (inc/coh) X-ray scatter ratio; ${ }^{\mathrm{c}}$ coh $=$ coherent $(\mathrm{coh})$

X-ray scatter, ${ }^{d} \mathrm{I}+\mathrm{C}=$ incoherent + coherent $(\mathrm{ich}+\mathrm{coh}) \mathrm{X}$-ray scatter; ${ }^{\mathrm{e}} \mathrm{clr}=$ centered $\log$-ratio, ${ }^{\mathrm{f}}$ alr $=$ additive $\log$-ratio.

\section{References}

1. Croudace, I.W.; Rindby, A.; Rothwell, R.G. ITRAX: Description and evaluation of a new multi-function X-ray core scanner. Geol. Soc. Spec. Publ. 2006, 267, 51-63. [CrossRef]

2. Rothwell, R.G.; Croudace, I.W. Twenty Years of XRF Core Scanning Marine Sediments: What Do Geochemical Proxies Tell Us? In Micro-XRF Studies of Sediment Cores. Developments in Paleoenvironmental Research; Croudace, I., Rothwell, R., Eds.; Springer: Dordrecht, The Netherlands, 2015; Volume 17, ISBN 978-94-017-9848-8.

3. Rothwell, R.G.; Rack, F.R. New techniques in sediment core analysis: An introduction. Geol. Soc. Spec. Publ. 2006, 267, 1-29. [CrossRef]

4. Tjallingii, R.; Röhl, U.; Kölling, M.; Bickert, T. Influence of the water content on X-ray fluorescence corescanning measurements in soft marine sediments. Geochem. Geophys. Geosystems 2007, 8, 1-12. [CrossRef]

5. Boyle, J.F.; Chiverrell, R.C.; Schillereff, D. Approaches to Water Content Correction and Calibration for $\mu$ XRF Core Scanning: Comparing X-ray Scattering with Simple Regression of Elemental Concentrations. In Micro-XRF Studies of Sediment Cores. Developments in Paleoenvironmental Research; Croudace, I., Rothwell, R., Eds.; Springer: Dordrecht, The Netherlands, 2015; Volume 17, pp. 373-390; ISBN 9789401798495. 
6. Hennekam, R.; de Lange, G. X-ray fluorescence core scanning of wet marine sediments: Methods to improve quality and reproducibility of highresolution paleoenvironmental records. Limnol. Oceanogr. Methods 2012, 10, 991-1003. [CrossRef]

7. MacLachlan, S.E.; Hunt, J.E.; Croudace, I.W. An Empirical Assessment of Variable Water Content and Grain-Size on X-ray Fluorescence Core-Scanning Measurements of Deep Sea Sediments. In Micro-XRF Studies of Sediment Cores. Developments in Paleoenvironmental Research; Croudace, I., Rothwell, R., Eds.; Springer: Dordrecht, The Netherlands, 2015; Volume 17, pp. 173-185; ISBN 9789401798495.

8. Gregory, B.R.B.; Patterson, R.T.; Reinhardt, E.G.; Galloway, J.M.; Roe, H.M. An evaluation of methodologies for calibrating Itrax X-ray fluorescence counts with ICP-MS concentration data for discrete sediment samples. Chem. Geol. 2019, 521, 12-27. [CrossRef]

9. Lee, A.S.; Huang, J.J.S.; Burr, G.; Kao, L.C.; Wei, K.Y.; Liou, S.Y.H. High resolution record of heavy metals from estuary sediments of Nankan River (Taiwan) assessed by rigorous multivariate statistical analysis. Quat. Int. 2019, 527, 44-51. [CrossRef]

10. Woodward, C.A.; Gadd, P.S. The potential power and pitfalls of using the X-ray fluorescence molybdenum incoherent: Coherent scattering ratio as a proxy for sediment organic content. Quat. Int. 2019, 514, 30-43. [CrossRef]

11. Agarwal, B.K. Scattering of X-rays. In X-Ray Spectroscopy. Springer Series in Optical Sciences; Springer: Berlin/Heidelberg, Germany, 1991; Volume 15, pp. 223-239.

12. Weltje, G.J.; Tjallingii, R. Calibration of XRF core scanners for quantitative geochemical logging of sediment cores: Theory and application. Earth Planet. Sci. Lett. 2008, 274, 423-438. [CrossRef]

13. Hunt, J.E.; Croudace, I.W.; MacLachlan, S.E. Use of Calibrated ITRAX XRF Data in Determining Turbidite Geochemistry and Provenance in Agadir Basin, Northwest African Passive Margin. In Micro-XRF Studies of Sediment Cores. Developments in Paleoenvironmental Research; Croudace, I.W., Rothwell, R., Eds.; Springer: Dordrecht, The Netherlands, 2015; Volume 17, pp. 127-146; ISBN 9789400720596.

14. Kylander, M.E.; Ampel, L.; Wohlfarth, B.; Veres, D. High-resolution X-ray fluorescence core scanning analysis of Les Echets (France) sedimentary sequence: New insights from chemical proxies. J. Quat. Sci. 2011, 26, 109-117. [CrossRef]

15. Chagué-Goff, C.; Chan, J.C.H.; Goff, J.; Gadd, P.; Oliva, F.; Peros, M.C.; Viau, A.E.; Reinhardt, E.G.; Nixon, F.C.; Morin, A. Late Holocene record of environmental changes, cyclones and tsunamis in a coastal lake, Mangaia, Cook Islands. Isl. Arc 2016, 25, 333-349. [CrossRef]

16. Oliva, F.; Peros, M.C.; Viau, A.E.; Reinhardt, E.G.; Nixon, F.C.; Morin, A. A multi-proxy reconstruction of tropical cyclone variability during the past 800 years from Robinson Lake, Nova Scotia, Canada. Mar. Geol. 2018, 406, 84-97. [CrossRef]

17. Lyle, M.; Oliarez Lyle, A.; Gorgas, T.; Holbourn, A.; Westerhold, T.; Hathorne, E.; Kimoto, K.; Yamamoto, S. Data report: Raw and normalized elemental data along the Site U1338 splice from X-ray fluorescence scanning. Proc. Integr. Ocean Drill. Progr. 2012, 320, 321. [CrossRef]

18. Penkrot, M.; LeVay, L.J.; Jaeger, J.M. Data report: X-ray florescence scanning of sediment cores, Site U1419, Gulf of Alaska. Proc. Integr. Ocean Drill. Progr. 2017, 341, 1-7. [CrossRef]

19. Lyle, M.; Kulhanek, D.K.; Bowen, M.G.; Hahn, A. Data report: X-ray fluorescence studies of Site U1457 sediments, Laxmi Basin, Arabian Sea. Proc. Int. Ocean Discov. Progr. 2018, 355. [CrossRef]

20. Babin, D.P.; Franzese, A.M.; Hemming, S.R.; Hall, I.R.; LeVay, L.J.; Barker, S.; Tejeda, L.; Simon, M.H. Data report: X-ray fluorescence core scanning of IODP Site U1474 sediments, Natal Valley, Southwest Indian Ocean, Expedition 361. Proc. Int. Ocean Discov. Progr. 2020, 361. [CrossRef]

21. Dunlea, A.G.; Murray, R.W.; Tada, R.; Alvarez-Zarikian, C.A.; Anderson, C.H.; Gilli, A.; Giosan, L.; Gorgas, T.; Hennekam, R.; Irino, T.; et al. Intercomparison of XRF Core Scanning Results From Seven Labs and Approaches to Practical Calibration. Geochem. Geophys. Geosystems 2020, 21, 1-13. [CrossRef]

22. Boyd, B.L.; Anderson, J.B.; Wellner, J.S.; Fernández, R.A. The sedimentary record of glacial retreat, Marinelli Fjord, Patagonia: Regional correlations and climate ties. Mar. Geol. 2008, 255, 165-178. [CrossRef]

23. Smith, N.T.; Shreeve, J.; Kuras, O. Multi-sensor core logging (MSCL) and X-ray computed tomography imaging of borehole core to aid 3D geological modelling of poorly exposed unconsolidated superficial sediments underlying complex industrial sites: An example from Sellafield nuclear site, UK. J. Appl. Geophys. 2020, 178, 104084. [CrossRef]

24. Miller, J.N.; Miller, J.C.; Miller, R.D. Statistics and Chemometrics for Analytical Chemistry, 7th ed.; Pearson Education Limited: Harlow, UK, 2018.

25. Plaza-Morlote, M.; Rey, D.; Santos, J.F.; Ribeiro, S.; Heslop, D.; Bernabeu, A.; Mohamed, K.J.; Rubio, B.; Martíns, V. Southernmost evidence of large European Ice Sheet-derived freshwater discharges during the Heinrich Stadials of the Last Glacial Period (Galician Interior Basin, Northwest Iberian Continental Margin). Earth Planet. Sci. Lett. 2017, 457, 213-226. [CrossRef]

26. Rodríguez-Germade, I.; Rubio, B.; Rey, D.; Vilas, F.; López-Rodríguez, C.F.; Comas, M.C.; Martínez-Ruiz, F. Optimization of Itrax Core Scanner Measurement Conditions for Sediments from Submarine Mud Volcanoes. In Micro-XRF Studies of Sediment Cores. Developments in Paleoenvironmental Research; Croudace, I.W., Rothwell, R.G., Eds.; Springer: Dordrecht, The Netherlands, 2015; Volume 17, pp. 103-126; ISBN 9789401798495.

27. Takahashi, G. Sample preparation for X-ray fluorescence analysis III. Pressed and loose powder methods. Rigaku J. 2015, 31, 25-30.

28. Currie, L.A. Nomenclature in evaluation of analytical methods including detection and quantification capabilities (IUPAC Recommendations 1995). Pure Appl. Chem. 1995, 67, 1699-1723. [CrossRef]

29. Gazulla, M.F.; Rodrigo, M.; Vicente, S.; Orduña, M. Methodology for the determination of minor and trace elements in petroleum cokes by wavelength-dispersive X-ray fluorescence (WD-XRF). X-ray Spectrom. 2010, 39, 321-327. [CrossRef] 
30. Linsinger, T. Application Note 1, Comparison of a Measurement Result with the Certified Value; ERM: Geel, Belgium, 2010; pp. 1-2.

31. Terashima, S.; Imai, N.; Itoh, S.; Ando, A.; Mita, N. 1993 compilation of analytical data for major elements in seventeen GSJ geochemical reference samples, “Igneous rock series”. Bull. Geol. Soc. Jpn. 1994, 45, 305-381.

32. Guevara, M.; Verma, S.P.; Velasco-Tapia, F.; Lozano-Santa Cruz, R.; Girón, P. Comparison of Linear Regression Models for Quantitative Geochemical Analysis: An Example Using X-Ray Fluorescence Spectrometry. Geostand. Geoanalytical Res. 2005, 29, 271-284. [CrossRef]

33. Imai, N.; Terashima, S.; Itoh, S.; Ando, A. 1994 Compilation of Analytical Data for Minor and Trace Elements in Seventeen Gsj Geochemical Reference Samples, "Igneous Rock Series". Geostand. Newsl. 1995, 19, 135-213. [CrossRef]

34. Mondal, M.N.; Horikawa, K.; Seki, O.; Nejigaki, K.; Minami, H.; Murayama, M.; Okazaki, Y.; Noda, M.; Wakaki, S.; Shin, K.-C. Glacial meltwater injection into the northern Gulf of Alaska from Cordilleran Ice Sheet insights from alkenone proxy records. Status (Unpublished; Manuscript in Preparation). Unpublished work.

35. Comas Cufí, M.; Thió-Henestrosa, S. CoDaPack 2.0: A stand-alone, multi-platform compositional software. In Proceedings of the 4th International Workshop on Compositional Data Analysis, CoDaWork'11, Girona, Spain, 10-13 May 2011; pp. 1-10.

36. Ziegler, M.; Jilbert, T.; De Lange, G.J.; Lourens, L.J.; Reichart, G.J. Bromine counts from XRF scanning as an estimate of the marine organic carbon content of sediment cores. Geochem. Geophys. Geosystems 2008, 9, 1-6. [CrossRef]

37. Cartapanis, O.; Tachikawa, K.; Bard, E. Latitudinal variations in intermediate depth ventilation and biological production over northeastern Pacific Oxygen Minimum Zones during the last 60 ka. Quat. Sci. Rev. 2012, 53, 24-38. [CrossRef]

38. Seki, A.; Tada, R.; Kurokawa, S.; Murayama, M. High-resolution Quaternary record of marine organic carbon content in the hemipelagic sediments of the Japan Sea from bromine counts measured by XRF core scanner. Prog. Earth Planet. Sci. 2019, 6, 1-12. [CrossRef]

39. Aitchison, J.; Egozcue, J.J. Compositional data analysis: Where are we and where should we be heading? Math. Geol. 2005, 37, 829-850. [CrossRef]

40. Thomson, J.; Croudace, I.W.; Rothwell, R.G. A geochemical application of the ITRAX scanner to a sediment core containing eastern Mediterranean sapropel units. Geol. Soc. Lond. Spec. Publ. 2006, 267, 65-77. [CrossRef]

41. Addison, J.A.; Finney, B.P.; Jaeger, J.M.; Stoner, J.S.; Norris, R.D.; Hangsterfer, A. Integrating satellite observations and modern climate measurements with the recent sedimentary record: An example from Southeast Alaska. J. Geophys. Res. Ocean. 2013, 118, 3444-3461. [CrossRef] 